\title{
LA LEGENDARIA VIDA DEL RENEGADO CALABRÉS UCHALI QUE DE ESCLAVO LLEGA A SER REY EN LA HISTORIA Y EN LA LITERATURA
}

\section{THE LEGENDARY LIFE OF THE CALABRIAN RENEGADE UCHALÍ WHO BEING SLAVE HE BECOMES KING IN HISTORY AND IN LITERATURE}

\author{
María Teresa Morabito \\ Università degli Studi di Messina \\ María LuISA TOBar \\ Università degli Studi di Messina
}

\begin{abstract}
RESUMEN
Este trabajo se centra en la legendaria figura del renegado calabrés Dionisio Galeno más conocido como Uchalí que por su valor y sus dotes de estratega en las guerras cristiano-turcas por el dominio del Mediterráneo, especialmente en la batalla de Lepanto, de esclavo llegó a ser Rey de Argel y Capitán General del Mar. Primero hemos examinado documentos y testimonios de coevos y también las primeras biografías para presentar su figura histórica y, segundo, hemos analizado como cronistas y poetas del siglo XVl y dramaturgos de principios del XVII recogen y transmiten la extraordinaria imagen de este esclavo y rey.
\end{abstract}

Palabras clave: Uchalí, esclavitud otomana, crónicas siglo XVI, poemas siglo XVI, teatro siglo XVII.

\begin{abstract}
This work is based on the legendary figure of the Calabrian renegade Dionysus Galen, better known as Uchali, that became king for his value and his skills as a strategist in the Turkish Christian wars for the domination of the Mediterranean, especially in the battle of Lepanthus, that he began as a slave to become then King of Algiers and Captain General of the Sea. At first we examined the documents and the coeval witnesses and also the first biographies to present the historical figure. Secondly, we have analyzed how 16th century journalists and poets and playwrights of the beginning of the 17th century collect and transmit the extraordinary image of this slave and king.
\end{abstract}

Keywords: Uchali, Ottoman slavery, 16 th c. Chronicles, 16th c.Poems, 17th c. Theatre. 


\section{RESUM}

\section{LA LLEGENDÀRIA VIDA DEL RENEGAT CALABRÈS UCHALÍ QUE D'ES- CLAU VA ARRIBAR A SER REI A LA HISTÒRIA I A LA LITERATURA}

Aquest treball es centra en la llegendària figura del renegat calabrès Dionisio Galeno, més conegut com a Uchalí, que pel seu valor i els seus dots d'estrateg en les guerres cristià-turques pel domini del Mediterrani, especialment en la batalla de Lepant, d'esclau va arribar a ser Rei d'Alger i Capità General del Mar. En primer lloc hem examinat els documents i els testimonis de coetanis i també les primeres biografies per a presentar la seua figura històrica i, en segon lloc, hem analitzat com cronistes i poetes del segle XVI i dramaturgs de principis del XVII recolliren i transmeteren l'extraordinària imatge d'aquest esclau i rei.

Paraules clau: Uchalí, esclavitud otomana, cròniques segle XVI, poemes segle XVI, teatre segle XVI. 
En este trabajo no pretendemos hacer una biografía sistemática de la vida de un personaje fascinante llamado Giovan Dionigi (Dionisio) Galeno que, al renegar de su religión toma el nombre de Uluch Alí, Uchalí, como le llama Cervantes en el Quijote, sino más bien trazar un esbozo de su recorrido vital deteniéndonos sobre todo en los aspectos más inherentes al tema general de esta publicación: la esclavitud. Ciertamente estamos ante un hombre de frontera con sus luces y sus sombras, amado y estimado por muchos que lo consideraban justo, generoso y conciliador; temido e incluso odiado por los que lo juzgaban despreciable, despótico y cruel, aunque todos reconocían su valor, su capacidad de mando y sus dotes de estratega en la guerra de corso, como bien demostró en los conflictos armados entre turcos y cristianos por el dominio del Mediterráneo, sobre todo en la batalla de Lepanto, donde fue el único de los generales turcos que consiguió no ser derrotado e incluso hacerse con algunas galeras cristianas.

No es extraño, pues, que ya en vida surgieran leyendas en torno a su persona y que los cronistas, poetas y dramaturgos se hayan hecho eco de sus empresas. Precisamente en la segunda parte de nuestro trabajo hemos analizado la figura de Uchalí en algunos textos literarios en los que el renegado calabrés ocupa un lugar preeminente entre los turcos: dos crónicas que se publican un año después de la batalla de Lepanto; tres poemas épicos escritos también a raíz de la contienda naval; y para terminar, nos hemos detenido en la dramatización que de este personaje hacen dos autores de principios del siglo XVII. 


\section{LA FIGURA HISTÓRICA DE UCHALI}

\section{El calabrés Dionisio Galeno se convierte en el renegado Aluch Ali}

La primera biografía de este legendario personaje se encuentra en el capítulo XVIII de Epítome de los Reyes de Argel, contenido en la Topografía e Historia general de Argel,' que fue publicada en 1612 por el abad de Frómista fray Diego de Haedo, el cual en la dedicatoria a su tío Don Diego de Haedo, arzobispo de Palermo, Presidente y Capitán General del Reino de Sicilia, firmada en Frómista el 25 de diciembre de 1605, dice que una de las razones por las que le dedica el libro es por haberlo compuesto él con las informaciones de cristianos cautivos "especialmente de los que se contienen en los Diálogos, que estuvieron muchos años en Argel, y habérmelos entregado, estando yo en Palermo en su servicio, aunque en borrón: de manera que sin el trabajo y diligencia que en ellos he puesto, dándoles la última forma y esencia, no se podían imprimir, ni sacar a luz". De estas palabras resulta evidente que fray Diego de Haedo es solo la persona que se encarga de recoger, ordenar y publicar los papeles que recibe de su tío el arzobispo de Palermo, no el autor de esos papeles.

Sin embargo, George Camamis (1877: 59 y ss, y 147) va más allá pues cree que, aunque Haedo haya publicado la obra con su nombre, el verdadero autor fue probablemente el benedictino Antonio de Sosa que fue compañero de Cervantes durante su cautiverio en Argel y que debió de escribir la obra entre los años 1577 y 1581 . Emilio Sola ${ }^{2}$ ratifica esta au-

1 La Topografía contiene cinco libros: Topografía de Argel, Epítome de los reyes de Argel más tres Diálogos: De la cautividad, De los mártires y De los Morabutos. El capítulo XVIII del Epítome está enteramente dedicado a la biografía de Ochalí, como se le llama en está obra (ff. 47r-95v). Pero también viene citado en numerosas ocasiones a lo largo de toda la obra.

2 Emilio Sola dice que después del espléndido estudio de Camamis "parece definitivamente esclarecida la autoría de la Topografía e Historia general de Argel, título genérico que engloba la «Topografía» propiamente dicha, el «Epítome de los reyes de Argel» y los tres «Diálogos», el De la cautividad, el De los mártires y el De los morabutos. Escrito en primera persona y con abundantes referencias autobiográficas que cuadran exactamente con el periodo de cautiverio de Antonio de Sosa en Argel -desde principios de 1577, en que llega a la ciudad con otras doscientas noventa personas cautivas de la galera «San Pablo», hasta después de mediado el año 1581-, ni el abad de Frómista Diego de Haedo ni su tío homónimo arzobispo de Palermo y gobernador de Sicilia, muerto en 1608, que nunca estuvieron en aquella ciudad berberisca, pudieron ser los autores de tan exhaustivo y abrumador texto. Diego de Haedo, por lo tanto, sería sólo el editor de aquellos manuscritos que trajo consigo a España en 1599 después de un viaje a Palermo, sin duda cedidos a su tío por el propio Antonio de Sosa; en 1604 había gestionado ya licencia para su publicación y, después de la muerte de su tío y del mismo Sosa, en 1612 los publica en Valladolid" (1991: 409). También se ha apuntado la posible autoría de Cervantes. EISENBERG, 1996: 32-33. Sin entrar en mérito al problema, pero reconociendo 
toría argumentando que un relato tan exhaustivo y abrumador solo podía proporcionarlo un testigo de los acontecimientos relatados. De hecho, las noticias referentes a Uchalí, sobre todo las de la época en la que Sosa estuvo cautivo en Argel (1577-1581), son tan puntuales que da la impresión de que están redactadas partiendo de apuntes tomados en el momento y en el lugar de los hechos, por lo que constituyen la biografía más completa y documentada de la vida de Uchalí.

El capítulo XVIII del Epítome, titulado Ochalí Bajá décimo nono [rey], empieza poniendo a Uchalí como ejemplo de los caprichos de la mudable fortuna, e inmediatamente resume en pocas líneas sus orígenes y primeros años de galeoto:

"Uno de los hombres en los cuales, en nuestros tiempos, la Fortuna quiso burlarse, como dice el Poeta, mostrando lo que pueden sus antojos, fue el Aluch Alí, a que corruptamente llamamos Ochali, porque Aluch, en morisco, significa lo mismo que nuevo moro o nuevo convertido, o renegado, $y$, ansí, no es nombre, mas sobrenombre, como el de renegado, y el nombre propio es Alí, y, ansí, Aluch Alí quiere tanto decir como el Renegado Alí. Hoy día no le llaman sino Alí Bajá, dejando el Aluch con que antes era llamado, pero, pues habemos de hablar con el vulgo como dijo Aristóteles llamarle, hemos Ochalí. Este era natural del Reino de Nápoles, de la provincia de Calabria, de un lugar pequeño, que está cerca del cabo de las Colonas, y que se dice Licasteli, de padres muy pobres y miserables. De su mocedad, se dio al oficio de pescar y de barquero: hasta que fue tomado y captivado de un corsario principal que se decía Alí Amet renegado griego que fue muchos años capitán de Argel en la mar. Y como era ya mancebo y recio, y en la mar criado y curtido, el Alí Amet le puso luego al remo de su galeota, en que bogó muchos años, y como era tiñoso, con la cabeza toda calva, recibía mil afrentas de los otros cristianos, que no querían a veces comer con él ni bogar en su bancada, y de todos era llamado Fartax, que en turquesco quiere lo mismo decir que tiñoso. Al último, dándole un día un levente (esto es, un soldado corsario) un bofetón, se hizo turco y renegado con intención de vengarse de él, pues siendo cristiano no lo podía hacer. Hecho turco su patrón sabiendo cómo era gentil marinero, le hizo a

los argumentos a favor de la autoría de Sosa, en adelante, citaremos la obra publicada por Haedo sin la indicación del autor, sino con el título de cada uno de los libros que contiene el texto citado. 
poco tiempo su cómitre, en el cual oficio ganó en pocos años buenos reales, con los cuales, y en compañía de otros tales armó en Argel una fragata o bergantín, y con éste robando por esos mares, vino a hacer una galeota y a ser uno de los mejores Araeces de Argel" (1612: ff. 77r-77v).

Además de la desaparecida Vita di Ulucciali, ${ }^{3}$ que en opinión del antropólogo Vito Teti es "opera di fondamentale importanza ancora in larga parte inedita" (2008: 144), Gian Giacomo Martini se ocupa de Uchalí también en Consiliorum (1635), ${ }^{4}$ obra en la que no solo hace referencia a su inédita obra Vita di Ulucciali sino que también habla del renegado calabrés en varias ocasiones. Por lo que se refiere a su nacimiento dice: "Giovanni Dioniso Galeno, chiamato tra i turchi Uluccialì calabrese di nascita, la sua patria era Le Castella vicino Crotone, figlio illegittimo di Birno Galeno e di Pippa De Cicco". ${ }^{5} \mathrm{Ni}$ en el Epítome ni en Martini se indica la fecha de nacimiento de Gian Dionigio Galeno, sobre la que se han hecho varias hipótesis. Gustavo Valente la coloca en torno a 1520 (1973: 134), propuesta poco probable pues contrasta con algunas relaciones de la época, como la del bailío recién llegado de Constantinopla, Gian Francesco Morosini, que en 1585 dice que Uchalí, entonces capitán del mar otomano, "di nazione calabrese nato vilissimamente in un luogo detto Li Castelli non sa né leggere né scrivere", y añade que en 1585 tenía casi 80 años y era tan "prospero e gagliardo" que suscitaba maravilla; un año antes Giacomo Soranzo, otro diplomático véneto, había dicho que Uchalí estaba cerca de los ochenta; y el bailío veneciano Lorenzo Bernardo, el mismo día de su muerte $(27$ de junio de 1587), en la semblanza que de Uchalí traza para el dux de Venecia Pasquale Cicogna, dice que tenía más de 80 años. ${ }^{6}$ Sola, después de un atento examen de los documentos, y basándose precisamente en que

3 Afortunadamente conocemos el texto de Martini gracias a la obra de Domenico Martire que según sus propias palabras toma totalmente de Martini: "Tutto il narrato d'Huccialì si è da me raccolto dalla vita manoscritta dell'abate Giangiacopo Martino nostro calabrese di S. Nicola di Valle Longa che imperfetta lasciò, e precoce dopo finita, darla alla luce, conforme egli stesso lasciò scritto nel suo volume de' Consigli impressi al consiglio $2^{\circ} \mathrm{n} .{ }^{\circ} 56^{\prime \prime}$ (Teti, 2008: 144).

4 Hay una edición moderna hecha por Vito Teti, (Roma, Donzelli, 2003).

5 Citado por Teti el cual, además, sobre los numerosos nombres que recibe Uchalí, escribe: "Giovan Dionigi Galeno, Giandionigi Galeni, d'Alucciali, d'Huccialì, Uluccialì, Aluccialì, Luzzalì, Uccialì, Ucciallì, Uichialì, Occhialì, Vuccialì, Vluzzalì, Vluccialì, Uluosch-Alì, Ouloudi-Alì, Uluch-Alì, Uludas-Alì, Euldi-Alì, Ulugh Alì, Kiliç Alì Pasha: la mobilità del nome è davvero emblematica della colorata «immagine» di un personaggio (o di tanti personaggi) e di una storia (e di tante storie) che raccontano di ambiguità e di conflitti, delle complessità e delle dinamiche identitarie, individuali e collettive" (2009: 144). Pero no son estas las únicas variantes que presenta el nombre, en los textos que hemos consultado hay otras. 
el bailío veneciano lo hace octogenario en el momento de su muerte, en 1587, supone que nació "entre 1503 y 1507 o en torno a 1518 como límite, según la cronología que emana del contador Alonso Sánchez, la mejor aproximación al calabrés de los servicios de información hispanos" (2010: 26). Sin embargo, si tenemos en cuenta que en el Epítome se lee que "en el año 1580 era de edad de 72 años y no estaba del todo cano" (f. 80v), la fecha de su nacimiento habría que colocarla en torno a 1508. De todas formas, este dato parece contrastar con la escueta descripción que en el mismo Epítome se hace de Gian Dionisio en el momento de su captura: "y como era mancebo y recio, y en la mar criado y curtido, el Alí Amet le puso luego al remo donde bogó muchos años" (f. 77v).

Otro punto en el que coinciden los biógrafos es que Giovanni Dionisio Galeno o Galeni nació en Le Castella (Crotone), una pequeña localidad en la Calabria Ultra bañada por el mar Jónico y que sus padres eran humildes pescadores: hijo de padres "muy pobres y miserables" se lee en el Epítome, hijo ilegítimo de humildes pescadores dice Martini y Morosini informa que nació "vilissimamente", es decir, de humilde y baja condición social; el bailío veneciano Lorenzo Bernardo añade que es analfabeto. Por el contrario Martire, siguiendo a Martini, dice que Gian Dionisio era "dotato di buon ingegno e che frequentava la scuola, con «lodevole profitto" (f. 554r). A finales de agosto de 1536 Jairedin Barbarroja asalta y saquea las costas calabresas y después de tres días de asedio a Le Castalla, el 28 de agosto el joven Dionisio según algunas fuentes es capturado por el renegado griego Alí Amet; también son capturados su madre Pippa di Cicco y su hermano menor de siete años, mientras su padre Birno muere en la lucha. El contador Alonso Sánchez, a principios de 1569, cuando Uchalí acababa de ser nombrado bajá de Argel, narra así la captura del joven Dionisio:

"Aluchalí, que agora es rey de Argel, es natural de la tierra de Le Castella, de la provincia de Calabria Ultra; llamábase por nombre Dionisio Galea. El cual, teniendo de edad 18 años, fue tomado del armada de Barbarroja, ${ }^{7}$ con él su madre, nombrada Pippa del Chicco y su hermano. Su madre y hermano del Aluchalí fueron llevados a Constantinopla. Él fue llevado a Natolia, de un corsario nombrado

6 Arch. di Stato di Venezia (en adelante ASV), Senato, Dispacci Costantinopoli, filze 25, ff. 413 $421,27 / 6 / 1587$.

7 El informe se conserva en el Archivo General de Simancas, que en adelante citaremos como AGS, Sección de Estado, leg. 487, doc. 122. 
Juseli Maymet, con quien estuvo a la cadena por esclavo, como cristiano, dos o tres años. Al cabo de ellos se hizo turco". ${ }^{8}$

Según el informe de Sánchez su madre fue esclava en Constantinopla durante siete años y al ser liberada volvió a Calabria pero no a Le Castella, lugar que había sido abandonado por sus habitantes, sino a Cutro donde estuvo hasta su muerte. En cambio su hermano que tenía siete años "hiciéronle turco en Constantinopla, adonde está con su mujer e hijos". Sánchez da también noticias de otros parientes de Uchalí que vivían o en Santa Severina o en Isola di Capo Rizzuto, pues "tomada la dicha terra delle Castelle, y quemada y arruinada, la gente que no se tomó, y la que después se rescató, se fue a habitar a Cutro, en l'Isola, en Cotrón y en Santa Severina". ${ }^{\prime}$

Por lo que se refiere a su captura y conversión al islamismo el relato de Martire se aleja, en parte, del de otros biógrafos; el autor calabrés, después de relatar el asedio y saqueo de Barbarroja a Le Castella y la muerte de Birno, dice que "Giandionigi figlio fatto Schiavo" y llevado a Constantinopla fue malvendido por ser tiñoso: "sendo giovane mal disposto, tutto tignoso, e di mala vista, fù venduto per vil prezzo ad un Corsale nomato Giafer da cui venne posto alle catene e al remo in una delle tre galeotte" (f. $554 r$ ). Parece que el joven esclavo conquista la confianza y simpatía de su dueño y de su mujer Martama, tanto que estando ella enferma Giafer lo dejó al su cuidado mientras él estaba ausente, la cual "ben'osservate le maniere d'esso Giandionigi, risolse di dargli per moglie una sua figlia, conche avesse lasciato la fede Cristiana". Al volver Giafer, informado del buen comportamiento de Gian Dionisio, lo empezó a tratar todavía mejor que en pasado y esto le procuró la envidia de otros dos esclavos de la casa, uno siciliano y otro napolitano, que envidiosos de su estado lo

8 El documento relativo a Alonso Sánchez se encuentra en el AGS, Sección de Estado, leg. 487, doc. 122. Noticias sobre la incursión de Barbarroja a las costas calabresas se encuentran también en AGS Estado, Nápoles leg. 1113 , f. 116, de 26 y 29/11/1537 y leg. 1025, doc. 103, de 29/11/1536; en AGS Estado, Sicilia, leg. 117/118 de 8/11/1536; y en AGS Estado "Nuevas de Levante", leg. 1025, doc. 104 desde el /11/1536.

9 AGS, Sección de Estado, leg. 487, doc. 122. Le Castella es el extremo de la localidad de Isola de Capo Rizzuto que era el lugar más expuesto, por eso Andrea Carafa, lugarteniente general de Nápoles entre 1523 y 1526, ordenó la reconstrucción de la fortaleza del islote adaptándolo a las modernas exigencias defensivas, lo que no impidió que el lugar fuera devastado por Barbarroja. Con el abandono del lugar empezó su decadencia que ha durado hasta la segunda mitad del siglo XX, cuando, gracias al turismo, se ha ido transformando hasta convertirse en una de las localidades balnearias más atractivas de la costa calabresa bañada por el mar jónico. 
"maltrattarono con villanie, in tal guisa che un giorno innanzi al padrone e per alcune parole il Napoletano die' uno schiaffo a Giandionigi. Ma costui tutto che fosse convalescente, gli replicò con un pugno sì gagliardo che fello subitamente morire. Tosto carcerato Giandionigi, fù in pericolo di perder la vita, se in tal emergenza non si fosse servita Martama dell'occasione, con indurlo a rinegar la fede, acciò che siffattamente avesse preso per moglie Vracadurna sua figlia. Quindi sbattezzato fù chiamato Uluccialì, tanto nominato tra' Cristiani e Turchi nel secolo passato per le varie prodezze da lui fatte sebbene in danno del Cristianesimo che ne sofferse le molte perdite dagl'Istorici decantate, oltre all'altre da loro taciute e forse non sapute. Uluccialì, questo sarà in avvenire il nome di lui, stante che negò la fede avanzandosi all'arte marinaresca e militare, d'astutia e di prudenza, venne impiegato in varie cariche, in cui troppo portossi ben col suo valore. Avvegnache nel seguente anno Giafer mandò Alì suo figlio in corso, e con esso lui Uluccialì, e accompagnatosi con Dragut Generale dell'armi Ottomane, ne contrasse grande amicizia, e per le sue maniere s'acquistò gran nome e riputatione appo al medesimo, e vi è più appo Solimano Imperatore de' Turchi allora regnante" (f. 554r-v).

La vida de esclavo de Gian Dionisio, sean pocos -como dicen Martire y otros autores-, o muchos -según el testimonio de Cervantes ${ }^{10}$ y Sosa- los años que pasó como tantos otros galeotes "amarrado al duro banco / de una galera turquesca, / ambas manos en el remo" [...] quejándose "al ronco son / del remo y de la cadena" (por decirlo con palabras de Góngora), no tuvo que ser fácil. Pues en su caso, a las duras condiciones de vida a que estaban sometidos los esclavos puestos al remo, hay que añadir las derivadas de su poco agradable aspecto físico, consecuencia de la enfermedad de la tiña que dejaba señales visibles. Esto hacía más penosa y dura su condición, pues tenía que soportar ser estigmatizado incluso por sus compañeros que no querían remar en su mismo banco ni comer con él. Como se lee en el Epítome "de todos era llamado Fartax, que en turquesco quiere lo mismo decir que tiñoso" (77v) y seguramente fueron muchos los

10 El cautivo cervantino dice: "Y ese Tiñoso bogó el remo, siendo esclavo del gran señor, catorce años, y a más de los treinta y cuatro de su edad, renegó de despecho de que un turco, estando al remo, le dio un bofetón y por poderse vengar dejó su fe (Don Quijote, I, XL). 
insultos, humillaciones, ofensas, vejaciones que tuvo que soportar hasta que abofeteado por otro esclavo napolitano reacciona matándolo; y si hasta entonces se había mantenido fiel a su religión, para no ser condenado a muerte ahora se convierte al Islam como única posibilidad de salvar su vida. Su conversión no solo le va a permitir adoptar el traje turco y, por tanto, cubrirse la cabeza con el turbante ocultando así las señales de su estigma, sino que además gracias a ella va a dejar de ser galeote pero no esclavo y pasa a ser cómitre y, según la narración de Martire, también yerno de Giafer, por haber esposado su hija Vracadurna.

\section{La llegada a la cúspide del poder de Uchalí}

A partir de este episodio, ya con el nombre de Aluch Alí, ${ }^{11}$ la suerte del esclavo calabrés cambia; con el dinero ganado como cómitre se hace con un barco y entra en la guerra de corsa robando, saqueando y capturando personas por las costas del Mediterráneo. Su afortunada intervención en la batalla de Los Gelves es determinante en su vertiginoso ascenso hasta llegar a la cúspide del poder. En el Epítome se resume así su escalada social:

"Dende entonces [la conquista de Los Gelves] creció mucho la fama y reputación del Ochali, y, particularmente, el Piali le quedó muy aficionado. Después, en el año del Señor de 1565, cuando la guerra de Malta, el Ochali se halló en ella, en compañía de Dargut Raez el cual siendo muerto sobre Santelmo de un golpe que le dio en la cabeza una piedra que saltó de Santelmo, donde una bala había dado, el Piali Bajá, como general del Turco en la mar y de todos los lugares marítimos, por la afición que tenía al Ochali, le hizo Rey y gobernador de Tripol, en lugar del Dargut muerto, cuyo cuerpo mandó que llevase a enterrar. Partióse el Ochali con tres galeotas de Malta, y llegado a Tripol se apoderó de cuantos baxeles, municiones, ropa, dineros, esclavos y hacienda quedara del mismo Dargut. Gobernó a Tripol dos años y medio, en el cual tiempo se hizo muy rico, ansí con lo que quedara de Dargut como con el continuo corso y robar que hacía, saliendo de Trípol y robando por todas las marinas de Sicilia, Calabria y Nápoles. Y como él hacía tanto caso y fundamento de la amistad de Piali Bajá, enviábale siempre ricos presentes. El

11 Las fuentes turcas y cristianas que documentan ampliamente sus correrías por todo el Mediterráneo, han sido atentamente examinadas en trabajos recientes, sobre todo en las biografías de Antonio Sola y Vito Teti, a las cuales remitimos para un estudio más completo. Sin embargo, por estar estrechamente relacionados con el tema de la esclavitud, recordaremos brevemente algunos episodios que se refieren a su relación con los esclavos. 
Piali, para gratificar estas buenas obras, hizo tanto que acabó con el Turco, como estando descontento del Mahamet Bajá, por lo que usara con los moros de Constantina, le enviase en su lugar por Rey y Gobernador de Argel: llegó como dijimos, a Argel en principio del mes de marzo del año de 1568" (ff. 77v-78r).

Al final del capítulo dedicado a Uchalí, en el Epítome se lee que los turcos lo tenían en gran reputación y que gobernó en todos los asuntos que tenían que ver con el mar con más poder y autoridad que ningún otro bajá y, además, se explica su tenor de vida:

"Hizo una muy grande y muy sumptuosa casa, en que vivía, cinco millas de Constantinopla, en la ribera o marina del canal de mar que de Constantinopla y Gálata va para el mar Negro, y luego, a poco espacio, hizo también una mezquita que toca dentro de la mar, muy grande, muy rica y sumptuosa, y cabe ella una cuba o sepultura muy linda y muy galana, a la usanza turquesca, en que después de muerto le enterraron. No tenía hijo ni hija, pero tenía más de 500 renegados de su casa, a que sustentaba y llamaba hijos" (f. 80v).

El bailío veneciano Bernardo, en la semblanza que hace de él, dice que nada más morir Uchalí, el Gran Señor dio orden de sellar todos sus bienes e inventariar todos sus esclavos y patrimonio, ${ }^{12}$ y añade que, entre otras cosas, tenía dos bellísimos serrallos sobre el canal, más de dos mil esclavos de los cuales más de 550 maestranzas en el Arsenal. El veneciano pone de relieve que el rápido ascenso que Uchalí consiguió por su gran valor, fortaleza e ingenio maravilló a todos y que era amado y estimado por los grandes hombres de la "Puerta", que acudían a él para que arbitrara en sus cuestiones. También dice de él que era un hombre liberal y magnánimo, "un bravissimo huomo non solo nella professione del mare, ma anco prattico et intelligente nelle cose del mondo", aunque también era "huomo crudelissimo et talmente colerico" que no se le podía llevar la contraria. Pero una de sus características principales era su frenético activismo que le llevaba a estar siempre en movimiento sin tregua ni descanso; él mismo decía que su vida era un continuo "travaglio", (término que hay que entender en su significado polisémico de fatiga, padecimiento, tribulaciones). Cons-

12 Murió sin dejar hijos por lo que el heredero de su gran fortuna era el sultán, aunque con él vivían 500 renegados a los que trataba como si lo fueran. Un hijo suyo llamado Carabey murió en la batalla de Lepanto, según Fernando de Herrera, como luego veremos. 
ciente de su posición y de su propio valer quiere dejar perenne memoria de su persona y para ello hace construir una mezquita en Constantinopla donde dispone que debe ser enterrado. En esta mezquita, intitulada a Kiliç Ali Pasá, situada a orillas del Bósforo, también conocida como la mezquita de Uchalí, yacen los restos de aquel cautivo despreciado hasta por sus mismos compañeros de esclavitud al que llamaban despectivamente El Fartax (el tiñoso) y luego, al renegar de su religión, Uluch Alí, (en sus numerosas variantes), para llegar a su último apelativo Kilic (espada tajante), que todavía pervive en este monumento a la memoria de uno de los hombres más poderosos del imperio otomano.

Martire también subraya que con sus propias hazañas se ganó el favor incluso del sultán:

"Furono tali e tante le prodezze di Hucciali, che per poterlo rimaritare Selim Imperatore, il fec[e] suo Supremo Ammiraglio dell'armata, e tutto che fosse di sangue villano il volle per suo genero, dandogli per moglie una sua figlia: posegli anche in fronte le corone di tre primi Regni dell'Africa, cioè d'Algieri, Tripoli e Tunisi. Alle conquiste de' quali, fatte in altre tempi dall'armata Spagnola, servì in parte $O$ in tutto l'ingegno e maestria di lui" (f. 560v).

\section{La relación de Uchalí con los cautivos, esclavos y renegados. ${ }^{13}$}

Pero como todos los grandes hombres, Uchalí tiene sus luces y sombras; por lo que se refiere concretamente a su relación con los esclavos y los

13 Robert Davis (2004) calcula que más de un millón de europeos cristianos fueron capturados y esclavizados en el norte de África desde principios del siglo XVI hasta mediados del siglo XVIII por los comerciantes de esclavos de Túnez, Argel y Trípoli. Se trata de un fenómeno muy complejo, que como bien dice Nicolas Vatin (2012) presenta variables y múltiples facetas. A partir de los últimos años del siglo XX estudiosos europeos y principalmente de la escuela francesa se han ocupado de la diferencia entre esclavos y cautivos. Podemos citar entre otros Wolfgang Kaiser $(2006,2008)$, que analiza la cuestión del uso del término cautivo. No pudiendo entrar aquí en mérito a la distinción jurídica y terminológica sobre cautividad y esclavitud, queremos solo advertir que usamos fielmente la terminología de las fuentes consultadas, en las cuales con frecuencia emplean indistintamente los dos términos, como se puede ver, por ejemplo en el Diálogo de la captividad y en el Diálogo de los mártires (vid. Nota 14). Ambos convivían en los baños: "Son también de notar los que llaman baños del Rey, que son las casas, corrales para mejor decir, do tienen sus esclavos y captivos cristianos encerrados" (Topografía, cap. 39, f. 42r). En la Información de Argel que Cervantes hizo de los cinco años que estuvo cautivo, habla siempre en términos de cautiverio, en cambio el escribano y notario Pedro Ribera que la recibe habla de esclavitud: "En la ciudad de Argel, que es tierra de moros, en la Berbería, a 10 días del mes de octubre, año de 1580, ante el ilustre y muy reverendo señor fray Juan Gil, redentor de España de la corona de Castilla por su majestad, (com)pareció presente Miguel 
cautivos, ya hemos visto que en el Epítome se afirma que a los quinientos que tenía en su casa los trataba como si fueran hijos y Cervantes, por boca del Cautivo, recuerda que "moralmente fue hombre de bien, y trataba con mucha humanidad a sus cautivos, que llegó a tener tres mil" (I, XL). También el bailío Bernardo confirma que sus esclavos eran muy bien tratados, pero al mismo tiempo precisa que eran tenidos tan estrechos y desesperados de obtener su libertad que cuando murió muchos sintieron gran alegría pensando que al pasar a ser propiedad del sultán conseguirían más fácilmente su libertad, a través de una venta o de la fuga. Con los no renegados, en cambio, con frecuencia se mostraba implacable y cruel, incluso parece que gozaba con sus sufrimientos. Leyendo la relación del Epítome sobre la vida de los cautivos de Argel se tiene la impresión de que, en ciertos casos, actuaba así para que nadie sospechase que su conversión al islamismo era solo de apariencia. En el Diálogo Primero, titulado De la captividad de Argel, ${ }^{14}$ los dos interlocutores, Antonio y Sosa, hacen una crónica detallada de la vida de los cautivos y su relato es un valioso testimonio del comportamiento de Uchalí con ellos. Hablando por ejemplo de la crueldad de los cómitres (todos turcos o renegados) para con los cristianos, sobre todo cuando se emborrachaban, Sosa recuerda lo que le habían contado que hizo Uchalí con un caballero de la orden de Malta que había capturado en 1569:

"Lo mismo me contaron que hacía ese sucio renegado Ochalí, Calabrés tiñoso, (a quien esta canalla tiene y estima por único, y rarísimo hombre del mundo) que fue General del Turco en la mar. Porque

de Cervantes - esclavo que ha sido, que ahora está franco y rescatado- y presentó el escrito de pedimiento siguiente, con cierto interrogatorio de preguntas"(2019). Tampoco es fácil saber cuando un renegado deja de ser esclavo, pues aunque al "tomar el turbante" queda exento de los trabajos más penosos por ser impropios de los hijos del profeta, no por eso deja automáticamente de ser esclavo, pero sí puede tener más oportunidades de conseguir su libertad. El caso de Uchalí que cautivado en Calabria es vendido como esclavo, se convierte en renegado y recobra su libertad, no es único en la época.

14 Este diálogo se configura como un tratado sobre la esclavitud en el que se hace su historia como aparece claro ya en el Argumento: "Entrando Antonio González de Torres caballero de San Juan, a visitar al Doctor Sosa su amigo, en las prisiones en que está captivo, y encarcelado, tratan los dos cuan infelice suerte sea la del captiverio, cuando tuvo principio el uso de hacer a los hombres esclavos, quien fue el autor de tan bárbara costumbre, de que manera y calidad era el captiverio, de que usaron antiguamente muchas naciones, y finalmente, de las grandes miserias, trabajos, tormentos y martirios, que hoy día padecen los captivos cristianos, en poder de moros y turcos, principalmente en Argel" (f. 96r). En adelante citaremos este diálogo como De la captividad, cuyos parágrafos se llaman "Divisiones". 
habiendo tomado entre otros a un caballero italiano, de nuestra Religión, cuando se perdieron sobre la Licata en Sicilia, las nuestras tres galeras de Malta: después algunas veces estando borracho, o (como otros dicen) cada día, decía a grandes voces: tomen aquel perro de San Juan, y denle 200 palos a la hora. De esta manera asiendo dél por los pies y manos; y echado de pechos sobre crujía, desnudo; si el Ochalí le mandaba 200 pasos, o azotes, le daban 300 y más; estando el Ochalí mirando esto en popa, riéndose muy contento de oír las voces del mezquino caballero" (ff. 117v-118r).

En otra ocasión, siendo ya Capitán General del Mar, le llevan a un cristiano que había matado a su amo y Uchalí, oyéndole contar que lo había hecho porque no podía soportar más las crueldades y maldades del patrón, y viendo la serenidad con que aceptaba su segura condena a muerte, se maravilla de la entereza del cristiano y se queda suspenso sin saber qué hacer. Probablemente hubiera querido perdonarlo, pero ante la presión y gritos de los parientes y amigos del muerto y quizás también por el temor de que pensaran que era tolerante con un esclavo cristiano, ordenó:

\begin{abstract}
"que con una maza de hierro (como se acostumbra entre ellos) le rompiesen todos los miembros, como brazos, piernas, espaldas y costillas. Y que desta manera le dejasen allí en mitad de la calle, que va de la aduana hacia el baño de los esclavos de Aluchalí para que con el tormento acabase de morir penando y los esclavos con mirarle escarmentasen" (f. 132r).
\end{abstract}

En el diálogo segundo titulado De los mártires de Argel, ${ }^{15}$ Gerónimo Ramírez y el doctor Sosa hacen un recorrido por la historia de los mártires y,

15 El Segundo de los Diálogo, De los mártires de Argel (en adelante Mártires), que tiene lugar entre Gerónimo Ramírez y el doctor Sosa, empieza con una breve introducción, o argumento, donde se da cuenta sintéticamente de su contenido: "Visitando el capitán Gerónimo Ramírez al Doctor Sosa su amigo en las prisiones, en que está cautivo; de un libro que le vio en las manos, tomaron ocasión de tratar, cuan provechosa cosa sea para todos, particularmente para cautivos, la lección de buenos libros, y en especial la vida de los Santos y Mártires de Dios. Y a este propósito se trata la vida del bienaventurado San Paulino, que en otro tiempo fue cautivo en Barbaría, y de los diversos modos, con que los tiranos y gentiles en otro tiempo mataban y atormentaban los cristianos, y cuéntanse también algunos martirios, y otras muchas y muy crueles muertes que turcos y moros han dado de pocos años acá a cristianos en Argel" (f. 144r). Después de un recorrido por la historia de los mártires cristianos pasa a tratar de los de Argel, donde es verdad que hay muchos renegados pero mirando bien, dice, se hallarán "aun más de siete mil otros que no solo no se han arrodillado ante Baal, pero admirablemente con su fe, vida y costumbres cristianas, y con una constantísima paciencia y esfuerzo, más que humano en los grandes trabajos y miserias que padecen, glorifican y honran en sí mismos y en sus cuerpos, a nuestro Señor Jesu Cristo" (f. 152v). 
al detenerse en la situación de Argel, Sosa dice a su interlocutor que para constatar lo que sucede allí basta que "eche los ojos por todos esos baños y casas, tanto deste bárbaro rey y tirano, cuanto de todos esos cosarios, turcos y moros, que número tan grande hallara en ellas"; sigue después la lista de las varias categorías de eclesiásticos, hombres de letras, soldados y personas de distintas lenguas y naciones:

"Y tantos otros infinitos cristianos, de toda nación, suerte y condición los cuales, como es lástima y piedad grandísima, verlos en tantas cárceles, tantas cadenas, tantas traviesas, y aun tantas mazmorras y martirios, apaleados, hambrientos, enfermos, desnudos, angustiados, aflictos y perseguidos del mundo, que realmente no es dellos digno" (152v).

De todo ello, ha tomado buena nota Sosa en unos papeles en los cuales con todas las diligencias del mundo ha ido anotando, como dice a su interlocutor, las informaciones recibidas de cristianos, renegados, turcos y moros sobre las crueles muertes de los cristianos desde el tiempo de Barbarroja hasta ese momento. Estos papeles, que Sosa da a Ramírez para que los lea, titulados Memoria de algunos martirios y otras muy crueles muertes que, estos años atrás, algunos cristianos han recibido, particularmente en Argel de los infieles turcos y moros, ilustran bien el trato que recibían los cristianos que no querían renegar de su fe. Damos solo tres ejemplos que ponen de relieve dos modos diversos de actuar de Uchalí. El primero se refiere a un episodio que tiene lugar el mismo año en que fue nombrado rey de Argel, el segundo al año sucesivo, y en ambos Uchalí da muestras de una crueldad inusitada; el tercero tiene lugar unos años después de la batalla de Lepanto, cuando ya era General del Mar y se nombraba Kiliç Alí Bajá, y su comportamiento es mucho más tolerante.

La primera historia tiene como protagonista a un mozo italiano llamado Gerónimo y sucedió a primeros de octubre de $1568,{ }^{16}$ pocos meses después de que Uchalí fuese nombrado rey de Argel. Había allí un italiano que siendo muy mozo le habían obligado a renegar su religión a la que luego volvió y que, tratando de huir de Argel para refugiarse en la cristiana Oran vestido de turco, le detuvieron unos árabes sospechando que era cristiano

16 Siete meses antes había llegado a Argel como gobernador: "El Piali, para gratificar estas buenas obras, hizo tanto que acabó con el Turco, como estando descontento del Mahamet Bajá, por lo que usara con los moros de Constantina, le enviase en su lugar por Rey y Gobernador de Argel: llegó como dijimos, a Argel en principio del mes de marzo del año de 1568" (Epítome, f. 78r). 
y al regístralo y no encontrar licencia alguna del rey lo prendieron y lo llevaron ante Aluch Alí. Interrogado por éste, confesó que era cristiano y que le habían obligado a renegar, pero que él quería seguir siendo cristiano y que por eso iba a tierra de cristianos; el rey, viendo su firme decisión de mantenerse en su fe, mandó que le llevaran al patíbulo y le desnudaron completamente y para burlarse de él los chauzes "le vistieron un coleto viejo de cuero y muy sucio, diciendo: que ahora con aquel vestido era cristiano y estaba muy galán y bizarro soldado". Luego le dieron muerte de la manera más cruel, según acostumbraban:

"Desta manera atándole por la cintura con soga, que conforme a lo que atrás otras veces habemos dicho colgaba de la garrucha, o polea que está en lo más alto de la horca, le alzaron hacia lo alto, y dejándole caer como es uso, con gran ímpetu abajo, y de golpe, en tocando al gancho, que abajo estaba con la punta hacia arriba muy grande y muy aguda, fue traspasado fieramente del, por el estómago, y de tal suerte, que la punta le salió por las espaldas" (f. 171v).

Y así lo dejaron tres o cuatro horas hasta que murió, es decir, desde el mediodía del 22 de octubre de 1568 hasta las cuatro cuando terminó de espirar.

Un año más tarde corrió una suerte parecida un moro que de niño había sido cogido en una razia y se convirtió al cristianismo y luego fue cautivado por los moros y llevado a Argel, donde quisieron que se convirtiera de nuevo al islamismo, pero él se mantuvo fiel en la fe de Cristo. Entonces, para que sirviese de ejemplo, Aluch Alí concibió para él una muerte cruel, murarlo en un bastión del fuerte que estaban haciendo para defender el embarcadero, cosa que ejecutaron de esta manera:

"No serían bien las tres horas del día y las nueve, como en España contamos, que entraron por el baño tres o cuatro ministros chauzes del Rey, y preguntando por Gerónimo, que estaba en la iglesia encomendándose a Dios, el mismo salió a ellos; los cuales como le vieron, luego como es de su costumbre, comenzaron con mucha braveza decirle mil afrentas y injurias, de cane, perro, cornudo, judío, traidor, ¿que por qué no quería ser Moro? A lo cual todo el siervo de Dios, no respondió ni aun una pequeña palabra. Los chauzes le tomaron en medio y caminaron con él hacia el fuerte o bestión (sic) que dijimos, donde el Rey le aguardaba, y había de ser su dichosa fin y muerte. Llegado pues a este lugar, y presentado delante del Rey, que 
estaba muy acompañado de renegados y Turcos, díjole el Rey estas palabras: Bre juppe, que quiere tanto decir, como Ola perro, ¿̇por qué no quieres tú ser Moro? Respondióle el mártir de Dios: no lo seré por ninguna cosa, cristiano soy, y cristiano tengo de ser. Replicóle el Rey: Pues si tú no te vuelves moro, allí (señalando el lugar de las tablas que dijimos con el dedo) te tengo de entapiar vivo. Respondióle el varón santo, con singular y admirable esfuerzo: Haz lo que quisieres, que aparejado estoy para todo: y ni eso me hará que deje la Fe de mi Señor Jesu Cristo. Visto por el Rey su grande ánimo y esfuerzo, y que tan constante estaba en la Fe de Jesu Cristo, mandó luego le quitasen la cadena que tenía a la pierna, y que atado de pies y manos le metiesen en el hueco de las tablas de la tapia, que mandara reservar el día antes; y vivo le tapiasen. Hicieronlo así los Chauzes. Y metido entre las tablas así ligado: un renegado español de casa de Agí Morato, el cual en cristiano se decía Tamago que cautivara en la pérdida de Mostagán con el conde de Alcaudete, y en Turquesco se decía lafer, saltó luego a pies juntos, sobre el mártir de Dios: y tomando en las manos uno de aquellos pistones que allí estaban, pidió con grande instancia, que trujesen presto la tierra: como trujeron, y echándola sobre el santo de Dios, que ni hablaba, ni abría su boca, más que un corderito manso, comenzó el renegado a dos manos con gran fuerza a pistar, dando con el pistón grandes y crueles golpes, lo cual viendo otros renegados de muchos que allí estaban con el Rey deseosos también de que los tuviesen a ellos por buenos y finos turcos, arremetieron también a otros pistones y cargando la tierra que se traía, y ellos pistando a toda fuerza y furia, acabaron de hinchar el hueco de las tablas, y de matar al glorioso mártir de Cristo, cuyo espíritu, conforme a nuestra santa fe, habemos de tener, que le recibió el Señor en el número de sus santos en el cielo, y que le dio la corona y premio desta santa y gloriosa muerte. A todo esto estaba presente el Rey y una infinita cantidad de Turcos, renegados, y Moros, mirándolo con gran contento y gusto. Lo cual hecho y quedando el cuerpo del santo varón sepultado en tan noble sepulcro, dio la vuelta el Rey para su casa, y decía por el camino, que realmente no pensara que aquel Cristiano recibiera la muerte con tanto ánimo. Sería entonces mediado Setiembre, del año mil y quinientos y sesenta y nueve" (f. 173r).

Al lado de episodios de crueldad extrema, como los que acabamos de citar, Sosa narra otros en los que Uchalí se muestra mucho más transigente. Tal es el caso del tercer episodio que hemos elegido como ejemplo, es de- 
cir, el de un acusado culpable de rebelión y asesinato contra su dueño. El 4 de febrero de 1577 los cristianos cautivos del corsario argelino Car Asán, que era muy cruel con ellos, estando en el río Tetuán, pensando que por la cercanía de España podrían escapar más fácilmente, se amotinaron hiriendo mortalmente al arráez. Pero fueron atacados por otra galeota mandada por Mamí Arráez, renegado de Car Asán, el cual ejecutó cruelmente a los mayores responsables:

"a Janeto el carpintero que había matado a Car Asan con la hacheta le cortan las orejas y las narices, le ahorcaron de los pies en la punta de la entena, y tiraron un gran número de flechas de forma que quedó como un erizo. Y luego le dejaron caer en el agua donde estuvo un gran cuarto de hora, después, creyendo que estaba muerto lo izaron y vieron que estaba vivo y lo tuvieron colgado como media hora hasta que murió. A Juliano le dejaron en calzones, le ataron atrás las manos y lo enterraron en la arena de la playa hasta la cintura y le arrojaron tantas flechas que todo el cuerpo quedó cubierto de ellas y luego echaron los cuerpos al río" (178v).

Pero, no conforme con esto, fueron a Argel para pedir justicia sobre los otros cristianos que creían más culpables. El rey dio licencia a Mamí Arráez para que atasen a Andrea laca a un caballo y lo arrastrasen por las calles de la ciudad hasta que, casi muerto, lo arrojaron desde la muralla donde quedó clavado en un gancho y murió; a Marcelo el calabrés lo ataron en un grueso palo donde le apalearon hasta romperle la cabeza y los miembros, y luego lo quemaron; al siciliano Marco Remolar lo ahorcaron los pies de una saetía donde estuvo colgado un día entero y al día siguiente lo echaron al mar. Y no satisfecho, pues quería matar a la mayor parte de los cristianos que habían tomado parte en la rebelión, Mamí Arráez fue a Constantinopla donde, junto con la mujer y los hijos de Car Asán, pidió a Aluchalí, que entonces era capitán general del mar, que hiciese justicia:

"pero el Aluch Ali, como hombre experimentado y cortido en las cosas de la guerra, y casos ordinarios della, no lo quiso consentir, antes les dijo, que fuera demasiada la venganza que tomara el Mamí Raez en Tetuán y Argel. Y mostrándoles el brazo derecho, que tiene estropeado les dijo: Veis aquí este brazo que cristianos esclavos, alzándose con un bajel mío en otro tiempo, y dándome muchas heridas por matarme y poder haber libertad, me estropearon, y ultra de esto se me han alzado con otros dos bajeles míos, y matado muchos turcos por alcanzar su libertad: y de todo no me he maravillado, porque todo 
cautivo y esclavo obligado es buscar modo y manera como salir de su cautiverio, y esta es la usanza de la guerra, y pues no solo fue Car Asan a quien esa suerte cupiese, quitaos desa demanda, y de querer matar a los pobres cristianos. Con estas y otras razones que les dio, los quietó el Aluch Alí: y les dijo muy llanamente la verdad, de cuan injustas crueldades fueron aquellas, que el Mamí Raez había hecho; juzgando que para dar tales muertes a cristianos no había causa justa ni bastante" (ff. 178v-179r).

El discurso que hace Uchalí en este caso, cuando está en la cúspide del poder, contrasta con su modo de proceder anterior, ya nadie puede dudar de su adhesión al islamismo pues ha demostrado suficientemente su aceptación contribuyendo de manera decisiva a la expansión del imperio turco y rechazando las halagüeñas promesas de los estados cristianos para que se pusiera a su servicio, por lo que no teme que puedan acusarlo de favorecer a los enemigos del islam. Pero sobre todo es significativa la afirmación de que los cautivos y esclavos están obligados a buscar el modo de ser libres, es una guerra y en la guerra se muere. Y pone como ejemplo lo que le acaeció a él mismo quince años antes. El episodio al que se refiere tuvo lugar en 1562, los documentos conservados en el archivo de Simancas dan minuciosa cuenta de lo ocurrido. Transcribimos la primera relación:

\section{"En Mecina a XII de Agosto 1562}

Relación de la galera capitana que fue del gran capitán Aloxalí la qual le fue levada de ocho renegados que son Paulo genovés de Onella, Hércules francés de Turs, Nicolo de Nixsia griego, Antonio de Cofando griego, Josep de Mendoça spañol, Demitrio griego de Nillo, Juan borgoñón, Luis spañol de Castro de Urdiales, Jac. ${ }^{\circ}$ Antonio de Otranto.

Dicen que estuvieron en Xio [Quíos] diez días son que fue los dos de agosto con Xx galeras capitanes de las quales eran Alli Portuch con las cuales era Aloxalí capitán de fanal el cual estaba destinando de ir con xv galeras de aquellas, o de otras que se speraban de Costantinopla para ir en Argel con la persona de Aser Baxa hijo de Barbaroxa que iba por Rey de Argel y que había de ir Aloxalí por capitán dellas y estas xx galeras andaban guardando el arcipiélago.

Que había hasta 40 días que trataban entre los ocho sobredichos de buscar ocasión de matar al Aloxalí y alzarse con la galera y que habían dado parte a algunos cristianos de la misma galera de los que más se fiaban. 
Que estando en Xio donde estuvieron VIII días y partiéndose de allí a 2 de Agosto a Complazecia de la tierra por el daño que les hacían se fueron al canal de Xio que es doze millas largo donde surgiendo la dicha galera vna milla más delante de las otras, se ofresció ocaisón que el capitán envió xx turcos en tierra en la propia isla de Xio a hazer carne y quedando hasta 120 entre renegados y turcos tomaron las armas y saltaron a la popa tres que son Paulo genovés, Hércules francés y Nicoló de Nixsia, los cuales mataron a Aloxalí con los que estaban en la popa y los echaron a la mar aunque se defendieron y hirieron al genoués en un brazo, y ansí hicieron en la proa Antonio de Cofando, Demitrio griego y Ja. ${ }^{\circ}$ burgoñón y los dos spañoles ayudaban donde era más menester y los forzados con las armas que se hallaron con puntales y babetas hizieron lo mismo contra los turcos y mataron más de 40 y los demás se echaron a la mar y ansí se alzaron a XXIl y dieron cargo de padrón de la galera a Phelipo Rizo de Crapi (sic) uno de los forzados y a Paulo Corso del cual se fiaron desdel principio más que de ninguno porque tenía la camera del medio en sus manos, y a otros hasta VIII dieron cargo de la galera para gobernalla que son Jo Celesti de Consençia, Baptista genoués, Franc.o de Nuza de Trápana, Baptista Perín genoués, Bernardino de Belneda, Renaldo de Seminara y Guillemo de Arbizora. Las galeras de enemigos les començaron a dar caza pero viendo que la galera era muy buena y caminaba mucho y la hora era tarde volvieron y no las vieron más y sin tocar en ninguna parte han venido en 9 días de Xio a Mecina.

Hay hasta 12 spañoles y hasta 32 genouenes y de otras naciones hasta en número de 160 cristianos entre todos. La galera es nueva de VI meses que ha que la echaron a la mar en Costantinopla, viene muy bien artillada y xarciada y muy bien en orden de todo lo necesario". ${ }^{17}$

17 AGS, Estado, leg. 1127-69. Esta relación va alegada a una carta del duque de Medinaceli a Felipe II del 18 de agosto de 1562 desde Monreale (Palermo) en la que, entre otros asuntos, habla de la presa de la galera de Uchalí y de su supuesta muerte: "La galera era de Uluchaly, de quien ya Vuestra Majestad debe tener noticia que era un renegado calabrés que ha mucho tiempo que era capitán de las galeras de Dragut y que hacía salidas por estas (sic) mares y el que fue cuando tocamos en los Gelves la primera vez a Costantinopla y truxo el armada de que ganó tanto credito y junto con ser valiente y experimentado, que había llegado a ser de mucha estimación entre los turcos y le habían dado fanal que es gran comienzo para ellos, ha sido de muy gran importancia su muerte porque fuera un muy dañoso perro para cristianos y a estos dos reinos que les tenía muy bien entendidos". Sigue diciendo que ha mandado que se compre la galera para su Majetad por ser la más hermosa que se ha visto, la mejor de la vela y el remo y también ha ordenado que se recompense a los que se alzaron contra Uchalí pues piensa "no solo por haber muerto un hombre de tanta importancia y haber salvado tantos cristianos mas porque es dar ánimo a los que allá quedan para venirse, que se yo que 


\section{UCHALI EN LA LITERATURA}

\section{Uchalí en las crónicas de Jerónimo Costiol y Fernando de He- rrera}

En 1572 Jerónimo Costiol, autor del que se conocen pocas noticias, ${ }^{18}$ publica una Crónica de la batalla de Lepanto (1572) en la que, como no podía ser de otra forma, dedica un amplio espacio al renegado calabrés que el cronista denomina Ochalí, aunque a diferencia de Herrera no hace ninguna referencia a su pasado de esclavo. En el capítulo XIII del libro II, se incluye un dibujo sobre la disposición de la batalla en el que se ven claramente las naves mandadas por Ochalí, junto a las de Caracossa, frente a la escuadra mandada por Andrea Doria.

En el capítulo XIV del libro II se habla de Ochalí destacando su capacidad de estratega, pues, prudentemente, pone en duda que las fuerzas de la armada cristiana fuesen tan reducidas como había informado el Corsario Caracossa quien, en su viaje de reconocimiento, seguramente no había podido ver todas las naves de la Liga que quedaban ocultas detrás de un promontorio.

"Ochalí empero gobernador de Argel, oyendo esta relación no la creyó: antes dixo que no era posible que los cristianos fuesen en tan poco número, porque por muy segura inteligencia sabía que era mucho mayor su armada, y que por ventura no lo había bien reconocido. Pero replicando el cossario, dixo que él lo tenía muy bien mirado, y que no se detuviesen por cosa alguna de salirles al encuentro, porque en una coyuntura como esta podían ganar mucho crédito, y aprovecharse bien. Partau, Bassan de tierra, fue de contrario parecer, concordando con el Ochalí diciendo que la Liga de tres potencias, con mayores fuerzas habían de venir: y que mirasen muy bien lo que determinaban, y que no era tiempo de tentar la fortuna en cosa incierta, esto es o sabiendo averiguadamente el número y poder de los cristianos, y que por tanto fuera mucho mejor estarse en el golfo de Lepanto, y aguardar allí a ver lo que sería" (ff. 58v-59r).

entendiendo que se haze bien con ellos haurá muchos que lo hagan y causará otra cosa de mayor consideraçión que será hazer odiosos y sospechosos a los Renegados con los Turcos que es la gente que más vale dellos, a lo menos en la mar" (AGS Estado leg. 1127-70). Pero la noticia de la muerte resultó ser falsa. Hay numerosos documentos en el AGS (legs. 1127 y 1128 ) relativos a la supuesta muerte de Uchalí y a los esclavos que se amotinaron contra él.

18 Sobre Costiol cf. LÓPEZ DE TORO, 1950. 
Pero cuando parecía que iba a prevalecer el consejo de Ochalí y de Partau, se levantó el turco Haly Aga diciendo que el mandato de Selin era pelear y que quien no estuviera de acuerdo se atuviera a las consecuencias cuando el Gran Señor examinase a los culpables, por lo que «Partau, Ochalí, y otros baxaes y capitanes, oyendo la repugnancia deste turco, y cuan zacudidamente lo trataba, determinaron por no parecer de menos ánimo, ir adelante» (L. II, c. XIV). Después, se describe la disposición de la batalla y se especifica que «El siniestro a la parte de mar llevaba el Ochalí gobernador de Argel, con Caracossa capitán de mar, según más claramente parecerá en la tabla siguiente». Inmediatamente, como ya se había hecho para los cristianos, se pone la tabla de las 230 galeras turcas y, según la lista, siete eran de Ochalí, el cual además aportó 12 fustas y 90 bergantines.

En la minuciosa descripción de la batalla, que ocupa varios capítulos, el cronista dedica amplio espacio a la acción llevada a cabo por Ochalí que en el lado del mar estaba dando grande trabajo a las galeras cristianas que mandaba Andrea Doria. En la descripción de la encarnizada lucha y los daños en ambos bandos, el narrador enfoca la acción de Ochalí, que con saña ataca las galeras malteses de San Juan de Jerusalén poniendo en grave peligro a su capitán el prior de Mesina, fray Pedro Justiniano:

"Porque teniendo Ochalí apretadísimo al Prior Justiniano, no peligró más su persona, de cuanto tardó a llegar don luan de Cardona con su galera. En la cual llevando al Marqués de Ávalos, y a don Henrique de Cardona a costa de mostrar solamente allí su cara, fue el maltés librado de muerte, de la cual ya no podía escusarse: porque el renegado Ochalí, con él, más que con otro quiso emplear su saña: y así hallándose no más de su persona sola con otros cuatro caballeros, le mataron todo el resto de su armada" (f. 67v). ${ }^{19}$

La oportuna llegada de la escuadra de socorro al mando de Juan de Cardona, capitán general de las galeras de Sicilia, salva al prior mesinés de la crítica situación. Más adelante, vuelve sobre el ataque del renegado calabrés a Fray Pedro Justiniano: «Y al Prior fue forçado dar razón a las galeras de Ochaly, que como está dicho cargaron sobre él» (L. II, c. XX).

19 Cervantes relata así el mismo episodio: "habiendo el Uchalí, rey de Argel, atrevido y venturoso cosario, embestido y rendido la capitana de Malta, que solos tres caballeros quedaron vivos en ella, y éstos mal heridos, acudió la capitana de Juan Andrea a socorrella, [...] Y como ya habréis, señores, oído decir que el Uchalí se salvó con toda su escuadra" (Quijote, I, XXXIX). 
La grave situación en que se encuentra Juan Andrea Doria se resuelve con la llegada de Barbarigo que enfrenta sus naves a las del corsario calabrés:

"Y hallando al señor Andrea muy apretado de Ochalí, y otros turcos sin él, que le habían desarmado de siete galeras, entró valerosamente en su socorro, y hizo retirar algún tanto al porfiado cossario. El cual no queriendo desde entonces abordar con alguno, peleaba con arcabuceros y flecheros aspérrimamente. Donde siendo herido de una dellas Barbarigo en un ojo, cayó por el pizuelo abaxo. Pero no por eso dexó su escuadra de pelear, porque como su Alteza andaba también por allí de una parte a otra, socorriendo donde vía que más era necesario, todo el mundo se movía muy bien. Ochalí a esta sazón volviendo los ojos a la real de España que con valentía lo andaba todo, y acabando de entender que la suya era perdida: entonces quiso abordar menos. Y así poco a poco arrimándose a la siniestra mano donde Barbarigo había peleado de primer encuentro, comenzó disimuladamente a ganar mar, para huir. Y acabando de ver casi la total destrucción de los suyos, comenzó gentilmente de hacer trinquete, para doblar una punta que a la parte de tierra estaba. Lo cual como viese su Alteza y el marqués de Santa Cruz, quisieron correr adelante para ganársela: y así fue forçado al enemigo envestir en tierra con algunas de las galeras que llevaba, de las cuales muchos turcos se escaparon a nado. Finalmente saliendo el Ochalí con parte de la banda que tras el iba, y rindiendo el señor Andrea las que quedaron sin escaparle una: la noche puso fin a la victoria, habiendo durado el sangriento conflicto desde las diez antes del medio día, hasta las cinco de la tarde" (f. 72v).

Es decir termina la relación de la victoria con la imagen de Ochalí escapando del escenario de la batalla con las galeras que pudo salvar.

En el capítulo IV del libro tercero, haciendo el recuento de las pérdidas turcas, nombra entre los muertos al hijo de Ochalí, Carabey, que era gobernador de Vzinith.

El papel relevante de Ochalí es puesto de relieve cuando, después de la derrota, Selín II consultó con algunos turcos expertos en las cosas de la guerra cómo poner remedio al desastre sufrido y ellos le aconsejaron "que pospuesto todo su enojo, que enviase por Ochalí que volviese con seguridad, para que venido ante él, se pudiese tratar mejor del remedio del negocio". Y así se hizo mientras "el Ochalí a esta sazón se entendió que estaba en Modón con siete galeras, herido de dos arcabuzazos y aguardaba orden 
del gran Señor que era lo que debía hacer: por eso de ir a Constantinopla, no sé yo si con todas las seguridades que el turco le podía dar, se tuviera él por muy seguro" (f. 86r).

El año sucesivo a la Batalla de Lepanto el poeta Fernando de Herrera escribe una obra en prosa titulada Relación de la guerra de Chipre y suceso de la batalla naval de Lepanto (1572). ${ }^{20}$ Aunque, como el mismo dice en la "Dedicatoria a D. Alonso Pérez de Guzmán duque de Medina Sidonia y conde de Niebla" no fue testigo de los hechos, su relato se basa en las narraciones de los que estuvieron en la batalla. Sin embargo, aun teniendo "grandísimo cuidado y diligencia" de elegir lo que le parece más razonable y lo que más concordaba entre las numerosísimas relaciones que llegaron a sus manos, e incluso preocupándose de interpelar a los que intervinieron en los hechos, es consciente de que es incierta la "verdad traída de partes tan remotas y de lenguas tan varias, y que todo no puede estar tan ajustado". Por eso, a veces, cita las fuentes de su relato y con frecuencia deslinda lo que le dicen de lo que piensa. Tal es el caso de la breve presentación que hace del calabrés al narrar el encuentro entre Ochialí y Alí Baxá en Negroponto cuando aquél, que entonces era virrey de Argel, había ido allí para limpiar el fondo de la nave y engrasarla. De hecho, el poeta sevillano dice que ese corsario renegado era "de nación calabrés, natural de Castelo lugar arruinado por Barbarroxa, que según dicen algunos que han estado en él", y luego, sin justificación alguna, añade: "yo pienso ser por ventura Castro, lugar en la costa entre el cabo de Santa María y Otranto, ocho millas distante del dicho puerto"(1572: XIV). Es decir, recogiendo la opinión de los pocos autores que sostienen que Uchalí era de Apulia interpreta el nombre Castello como Castro y no como Le Castella. Inmediatamente dice: "Que lo saquearon Lustimbey y Barbarroxa cuando iba con ellos Troylo Pinatelo en el año de treinta y siete y se llevaron presa toda la gente" (1572: XIV). De lo que podemos deducir, aunque no lo explícita, que Herrera considera erróneamente que la captura de Uchalí tuvo lugar en ese asalto a Castro que, efectivamente se hizo en julio de 1537, cuando Barbarroja instigado por Francisco I de Francia puso asedio repetidamente a esa ciudad situada en la punta donde se unen el Adriático y el golfo de Tarento.

Luego, hace referencia a las incursiones que Uchalí lleva a cabo por el Mediterráneo saqueando las localidades costeras y cautivando a sus habitantes:

20 La obra, publicada en 1572, carece de numeración, así pues en las citaciones además del año, ponemos entre paréntesis el capítulo correspondiente. 
"A este [Uchalí] por ser famoso entre los cosarios, y por la confianza que se hacía de su valor, envió a mandar el mesmo Selín desde Constantinopla [...] para que se juntase con su armada. Y obedeciendo su orden, salió de Argel, saqueando de camino todos los lugares de la costa, y con grande número de cautivos llegó a su armada" (1572: XIV).

Y sigue nombrando todos los lugares costeros por los que pasaba, precisando que en la isla de Candia llegó a cautivar a más de ochocientas personas y los mismos daños hizo en Zante y en Chafalonia de donde se llevó a más de "seis mil cautivos". También conquistó Corfú a los venecianos; y también tomó Dulcino, Buda y Antivari y salió de esa costa con más de "cuatro mil esclavos", aunque perdió cuatro galeras por una borrasca. Pero no consiguió hacer lo mismo en Cataro defendida con mucha gloria por Mateo Bembo.

Por lo que se refiere a la batalla de Lepanto, como todos los autores, Herrera resalta la importancia de Uchalí en la contienda. De hecho, en el capítulo sobre Los preparativos de la Liga y como los turcos tratan de reforzar su armada, leemos que Ochalí sacó de Modón más gente : "Que serían todos casi veinte y cuatro mil hombres. Porque (según afirma el comentador Romagaz) ${ }^{21}$ se había informado de Caracial y Caracossa, que tomando lengua en Calabria de la armada de la liga, volvieron con relación della al Baxá el que traía la más poderosa armada, que jamás la potencia Otomana pudo meter en mar" (1572: XXIII).

$Y$ en el capítulo XXVI, antes de entrar en el vivo de la batalla, Herrera escribe que los turcos no toman en serio a sus enemigos pues «al principio no podían descubrir todo el número de sus galeras, cubriendo una montaña casi la tercia parte dellas". E insiste en la prudencia de Uchalí que aconseja mirar bien lo que van a hacer pues las galeras Ponentinas, como suelen llamar a las de Felipe II, eran muchas, pues no era creíble que el rey mandase a su hermano a combatir sin fuerzas suficientes pero, al final, acata la orden del Baja de ir a combatir.

Luego Herrera presenta la formación y disposición de las dos escuadras. El escritor afirma que Uchalí aporta siete galeras, doce galeotas, y que guiaba el cuerno diestro opuesto a Juan Andrea Doria, con su hijo Carabey.

21 Seguramente se trata de Mathurin d'Aux de Lescout, conocido como Mathurin Romegas, noble gascón, miembro de la orden de San Juan de Malta, que fue uno de los comandantes navales más importantes de la Orden en la batalla de Lepanto, en la que combatió en el buque insignia papal bajo el mando del almirante Marco Antonio Colonna y era el superintendente de las galeras papales. 
Relata, además, la estrategia de Uchalí que se había alargado tanto "con el cuerno siniestro, que hubo duda que no quería pelear y pareció, que era su intento cerrar a los cristiano dentro de su escuadrón" y como Doria, dándose cuenta de la maniobra del renegado, contraataca. Herrera, no parece apreciar mucho la maniobra de Uchalí que achaca no a una sabia estrategia del calabrés, sino más bien a su intención de rehuir el combate con Andrea Doria cuya nave había reconocido por el fanal, pues dice: "Mas aunque Juan Andrea lo procurase mucho, rehuyó siempre Uchalí encontrarse con él, de suerte que ambos se hallaron siempre en parte diferente". Más adelante comenta: "Ochialí, que según muchos afirman, nunca peleó con su galera, viendo que llegaba socorro a la de Malta, se retiró a la batalla, y hallando todas las cosas en desorden, huyó con el estandarte de la Religión". Herrera contrapone el comportamiento heroico del genovés al cauteloso de Uchalí que parece que lo único que pretende es evitar entrar en batalla con un rival al que teme por su fama y escapar con vida, aunque no sin antes haber atacado duramente a la galera de Malta.

Aunque no ha sido testigo de los hechos, Herrera afirma persiguir la verdad con más empeño que nadie, cotejando todas las relaciones que conoce para dar la que cree mejor versión de lo acontecido en la batalla; en el caso de Uchalí no parece que esto sea así, pues no solo elige la versión equivocada por lo que se refiere a su patria y cautiverio, sino que también parece que quiere dejar en sombra la victoria parcial conseguida por él en Lepanto.

\section{Uchalí en los textos poéticos de Pedro Manrique, Jerónimo Costiol y Jerónimo Corte Real}

Hay dos poemas manuscritos dedicados a la Batalla de Lepanto, La naval y La victoria que tienen por autor a Don Pedro Manrique. El primero, un volumen encuadernado en pergamino con el título y el autor solamente en el tejuelo y sin ningún tipo de título o autoría en el texto, se conserva en la biblioteca Nacional de Madrid (Mss 3942); el segundo, con elegante encuadernación en piel con el escudo de Castilla (aunque bastante estropeada), además de en el tejuelo, tiene también en la primera pagina el título y el nombre del autor, Pedro Manrique, el cual firma la dedicatoria a Don Juan de Austria en Burgos a 20 de abril de 1573. Este segundo códice forma parte de los fondos españoles de la Biblioteca Mazarine de París (Ms

22 No es ésta la sede para hacer un análisis cotejando los dos manuscritos que nos permitiría avanzar hipótesis sobre la relación de dependencia de ambos textos, así pues nos limitaremos a decir que creemos plausible que La victoria sea una nueva versión, casi una reescritura, quizá para la imprenta, de La naval. 
1843). ${ }^{22}$ En los dos casos hay suficientes indicaciones explícitas o implícitas para afirmar que el autor participó en la batalla de Lepanto. Ni López de Toro que ha incluido La naval en su estudio sobre los poetas de Lepanto (1950: 56-61), ni Cioranescu, que ha escrito un ensayo sobre La victoria (1952: 37-49), han podido averiguar quien era Pedro Manrique. En base a una minuciosa investigación creemos poder sostener que el Pedro Manrique autor de este poema sobre la batalla naval de Lepanto pertenecía, por línea materna, a la familia de los Manrique, siendo el segundo hijo de Juan de Santo Domingo y de Doña María Manrique de Luna y sobrino de Don García Manrique fundador del colegio Manrique donde estudió Pedro. De hecho, en la Historia de la Casa de Lara se da cuenta de su participación en la batalla de Lepanto:

“D. PEDRO MANRIQUE, que está nombrado en el testamento, y mayorazgo de sus padres, y es quien D. Garcia Manrique de Luna su tío dejó la presentación de una beca del Colegio Manrique, siguiò la milicia, y después de haber hecho muchos servicios a Felipe II, se halló en la batalla de Lepanto el año 1571 donde peleó tan valerosamente, que $\mathrm{S}$. Pio $\mathrm{V}$ le concedió jubileo plenísimo el día 7 de Octubre de cada un año para la Capilla del S. Cristo de la Trinidad de Burgos: la cual y la Capilla de N. S. del Rosario, y la escalera referida, que está en medio dellas, adornó este Caballero con los retablos, y con los bultos y armas de sus padres, y otras cosas. Y en cada una desta dos Capillas hay dos banderas que dicen los Religiosos haberlas ganado en la batalla de Lepanto. Murió D. Pedro en Portugal sirviendo a Felipe II y por no haber casado, ni tener sucesión heredó sus bienes Doña María su madre, que respecto de ser fallecido, no hace memoria dél en el testamento que otorgó en 9 de Enero de 1580. Pero Don Alonso su hermano, que le amó mucho, dispuso, cinco años después, que su herencia se gastase en las obras pías que adelante referiremos" (Salazar y Castro, 1694: 522).

Se trata de otro soldado-poeta más que versifica unos hechos de los que ha sido testigo presencial. En su obra, Luchaly, como viene nombrado en el poema, ocupa un lugar relevante entre los personajes de la escuadra otomana. Aparece por primera vez en el Canto I donde se dice que Marco Antonio esperaba con ansia la escuadra mandada por Andrea Doria (de la que Pedro Manrique formaba parte) y explica que el causante de su retraso es Luchaly: 


\begin{abstract}
"Tardamos porque entonces vino nueva
del falso Luchaly, que tan pujante navega, que veinte y ocho velas lleva más que no el viento vano y arrogante, éste es un renegado cierta prueba de que es Fortuna infiel, y aun inconstante, fue un pobre calabrés, después esclavo, a quien un bofetón dio un turco bravo.

Del remedio perdida la esperanza mirad un gran rancor adonde llega, que a trueque de entregarse en la venganza de Dios, y de su santa Fe reniega" (ff. 9v-10r).
\end{abstract}

Es significativo que las primeras palabras que Manrique dedica a Luchaly sean para calificarlo de falso, pero reconociendo al mismo tiempo su vigor de navegante aunque vano y orgulloso, cualidades que definen bien al renegado calabrés que se hace turco no por una conversión sincera sino porque habiendo recibido un bofetón no encuentra otra forma de vengarse de la ofensa recibida que la de abrazar el islamismo. La decisión tomada le llevará a hacerse rico y famoso. Y al renegar de su fe, añade, entrega su alma al diablo, se hace corsario junto a otros pobres con tan buena suerte "que vino de un esclavo y vil cosario / A verse rey de Tripol, ved su suerte /Y aun rey de Argel, a Hespaña tan contrario " (ff. 10v-1 1r).

Narra, luego, como Andrea Doria trata inútilmente de darle caza por todo el Mediterráneo, y como Luchaly no solo le hace perder su pista, sino que además consigue cobrar tributos a los nuevos reinos conquistados y apresar algunas naves cristiana entre Malta y Sicilia. Manrique de esta guerra de corso entre Andrea Doria, su comandante, y Luchaly describe minuciosamente la mutua persecución de las dos escuadras. Damos un ejemplo en el que el soldado poeta justifica la victoria de Luchaly por la superioridad numérica de sus naves:
"A quien ya Juan Andrea con pecho osado
en vano le buscó, qu' es gran astuto
en la Pantanalea desarbolado
estuvo, y en el Cymbano sin fruto,
porque en Biserta estaba el renegado 
tomando al nuevo reino su tributo.

El cual salió de allí, porque ya que espía

y en el canal de Malta se metía.

Porque estando en la guarda una galera

suya, acertó a tomar cierta fregata

que salió de Sicilia y dio manera

a Luchaly, según lo que relata

para que salga, y sale, y las espera

que su solicitud nada dilata,

la cual le dijo el punto cuando parte

el general de Malta y a que parte.

De Malta las galeras animosas

quel mar siempre sulcaron con buen viento

buscaron nuestra armada presurosas

queriendo concurrir a un mismo intento

por fin de un capitán, y ciertas cosas

a Malta van con este fundamento

desde Sicilia, y fiero las aguarda

aquese rey de Argel, con mucha guarda.

Al alba Luchaly tuvo tal tino

que al general da caza y se apresura

las nuestras no confirman el camino

que no hay para el temor parte segura.

Las dos fueron al mar y su destino

les puso entre enemigos sepultura,

la fuste capitana a tierra corre

la cuarta se amparó con una torre.

Con sus veinte y ocho velas, ved que espanto,

a cuatro acometió, mas aunque fiera

sin grande resistencia, ni quebranto

tomó a la religión las tres galeras,

presa que debe con perpetuo llanto

llorarse, pues se pierden sus banderas" (ff. 10v-1 lv). 
Luego, resalta la codicia del renegado calabrés que no descansa y aspira a cobrar siempre nuevas presas con que aumentar su riqueza y poder y así con " una codicia atroz, y una vil ira" se dirige a Grecia, luego a Candía y a otras islas, hasta llegar a Negroponte como caudillo de los corsarios (f. $12 r$ ).

El autor, como todos los que describen el combate naval de Lepanto, también detiene su mirada sobre Uchalí que con doce embarcaciones sale de Argel de donde "vienen veloces prósperas galeras / y en ellas hombres de admirable traza" (f. 287) a las que se añaden nueve de Balagi de la Velona, las trece de "aquel Carabey que es hijo astuto / del fiero Luchaly [...]" (f. 233r), las quince de Carachaly que también había sido esclavo y otras más que componen cuerno izquierdo. También Manrique dice que Luchaly evita la lucha frente a frente con Doria: "No busca al 'Oria el rey d'Argel que busca / combatir sin peligro, está a la mira / ve tanta muerte y roja luz corusca / que con sartas y galeras se retira" (f. 366r). Sin embargo, sí se enfrenta con la nave de Malta que desdichadamente sucumbe al ataque de Luchaly. Manrique no se limita a narrar los hechos sino que además expresa su dolor por la suerte de los caballeros de Malta: "De todo más que todo me lastima / de aquella religión la triste historia / del fiero calabrés que así se anima / a conseguir con ellos gloria" (f. 385v). Insiste en la fiereza del renegado y sobre todo en que acomete con ventaja pues "anduvo cauteloso que es astuto / mirando cómo a cada cual le fuese / estaba en la batalla resoluto / de se portar en ella, como viese" (f. 385v), una actitud cautelosa pero cobarde que le permitió cobrarse las banderas malteses y dar muerte a casi todos. Manrique termina su narración insistiendo en la barbarie y en la cobardía de Luchaly que, cuando se ve en peligro procura ponerse en salvo, pero reconoce "que es astuto y sagaz de ingenio agudo" (f. 395r). Además de la Crónica sobre la batalla de Lepanto, de la que antes hemos hablado, Costiol publica, como segunda parte de ésa, un poema titulado Canto al modo de Orlando de la memorable guerra entre el gran Turco Selino y la Señoría de Venecia. Con la felicísima victoria del Serenísimo Señor Don Juan de Austria, general de las armadas de la confederación Cristiana, en el que reescribe poéticamente los mismos argumentos, es decir la guerra de Chipre y la batalla de Lepanto. Como apunta el título, a imitación del Orlando de Ariosto, es un poema en octavas dividido en tres cantos que, como él mismo dice en el "Prólogo al lector", ha traducido (aquí no dice de qué lengua, pero en el epígrafe especifica que es del italiano), aunque, añade, que algunas estancias son suyas.

En el Canto Segundo en el cual se contiene la conclusión de la Sancta Liga, y la llegada del señor Don Juan de Austria a Mesina, donde se ayuntaron las armadas de la confederación, Costiol alude a como Ochialí había 
acumulado sus riquezas en la guerra de corso y a su incorporación a la armada turca junto con Caracossa:

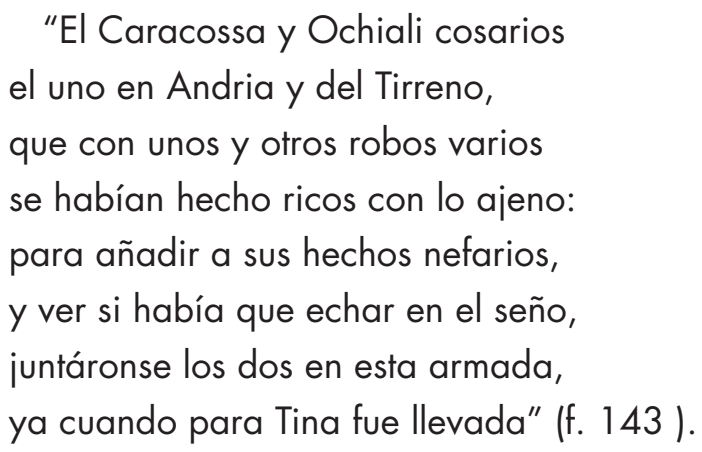

Más adelante, al narrar lo pormenores de las correrías de Ochalí antes de juntarse con la armada turca que se está preparando para la batalla contra la Liga, dice que implacable ataca las costas del Adriático, asolando y saqueando las localidades costeras, matando y haciendo numerosos cautivos:

"Ochali, Caracossa juntamente, que licencia del general tuvieron, tomando su camino diferente, después que del Dulciño se partieron: subiéronse por el oriente, a do notables males nos hicieron, sobre Liesena, y Corsula robado, todo lo que pudieron y quemando.

Después de haber su crueldad hartado, con sangre de la gente baptizada, y haber no pocos dellos captivado, y allá dejando la tierra abrusada: dallí volverse presto han acordado, para juntarse luego con l'armada, tópanse en fin con grandes alegrías jactándose de muchas valentías" (f. 157). 
En el Canto Tercero, en el cual se cuenta la batalla de las armas infiel y cristiana, y la victoria del valerosíssimo capitán don luan de Austria, Costiol describe la formación de la batalla y por lo que se refiere al puesto ocupado por Ochalí dice:

"Digo quel cuerno derecho señalaron

al cosario Sirocco, gran tirano:

con él a Mahometh Bey juntaron

otro tal como el Turco inhumano.

Al Ochalí el izquierdo encomendaron, con Caracossa de la brava mano,

y ansí venían ellos confiados,

de luego nos tragar en dos bocados" (f. 164).

Es decir, a diferencia de otros poetas, testifica solamente la presencia en la batalla del rey de Argel, sin describir ninguno de sus movimientos, ni siquiera alude a su ataque a la nave de Malta ni a su fuga cuando ve que todo está perdido.

El poeta, músico y pintor portugués Jerónimo de Corte Real, ${ }^{23}$ escribe la Espantosa y felicísima victoria (1575), ${ }^{24}$ un extenso poema sobre la batalla de Lepanto dividido en 15 cantos cada uno de los cuales está ilustrado por un grabado realizado por el mismo autor. De hecho, en el Prólogo dedicado a Felipe II, escribe que para componer sus versos se valió de "las más verdaderas informaciones, que [le] fueron posibles, tomando la substancia de aquellas que aunque de varias partes [le] fueron traídas, al fin se reducían todas a la misma opinión"; también dice que ha elegido escribir en castellano, a pesar de las críticas, avalado por sus abuelos los Mendoza y los Bazanes para que "la variedad de las colores y la invención de la pintura" a la que S. M. es inclinado "haga fácil aquel peso y molestia de una lectura falta de invención y de aquel ornamento y polido estido que en los grandes ingenios, solo se hallan". En la obra de Corte Real los elementos históricos narrados minuciosamente se mezclan con elementos propios de la épica clásica que imprimen a la narración un tono mítico.

Al final del Canto IV aparecen en el horizonte ocho sedosas velas con las que Uchalí va encontrarse con el gran Bajá quien, esa misma noche, ha

23 Sobre el autor cf.: Lopes de Almeida, 1979.

24 El manuscrito se conserva en la Biblioteca Nacional de España (Mss 3693). Hay una edición de 1578 publicada en Lisboa por António Ribeiro. 
tenido un sueño premonitorio que termina con la visión simbólica de la futura derrota turca pintada en el escudo de Don Juan de Austria. Las galeras de Ochalí con centenares de naves venidas de varias partes se concentran en Negroponto a las órdenes del gran Bajá, en espera de la batalla, pero Ochalí, que no sabe estar inactivo, se hace a la mar de nuevo donde sigue asolando los lugares costeros. Sus correrías son cantadas en el capítulo V, en el que el rey de Argel es protagonista indiscutible, como se anuncia en el epígrafe: Estando la armada turquesca en Negroponto esperando por soldados de la Morea, Ochialí rey de Argel juntándose con otras galeotas de Cossarios, van la vuelta de Candia, haciendo daño en algunos pequeños lugares: y lo mesmo hicieron al Zante y a Cefalonia, a donde dieron muerte a mucha gente, llevando otra mucha captiva. Lo primero que hace el poeta es presentar al personaje:
"No quiso el Ochialí bravo cosario pasar en ocio el tiempo, ni perderlo con sagaces cosarios va el maldito que recibió en Calabria l'agua santa del sagrado baptismo, en su primera edad, y la observancia dominica. Ay de ti Ochialí, que así trocaste la hermosura y la gracia del Olimpo por la hedionda, horrible escura cueva del tenebroso Averno y negra Estigie. Trocaste ver a Dios? A Dios trocaste por las pálidas sombras infernales trocaste gozo y gloria sempiterna por aflicción, tristeza, y amargura? Ay, ay de tu alma triste!, que rompido el mortal velo, irá do no ay consuelo, do se niega el placer, do siempre viven en tormento, en dolor, y en llanto esquivo" (Canto V, f.68r).

La presentación de Corte Real es atípica respecto a la de otros autores, pues, en línea con la estructura narrativa del poema, mezcla poéticamente los elementos reales con consideraciones personales en las que lo mitológico se entrelaza con lo religioso. Luego sigue explicando que, no queriendo 
perder el tiempo en ocio, mientras Alí Bajá reúne a los soldados de Morea y a valientes jenízaros, Ochialí sale de Negroponto con ocho galeras suyas bien provista y cuarenta y dos menores dirigiéndose con viento favorable a Corfú y Candia, donde cometen toda clase de crueldades llevando desolación y terror a las poblaciones por las que pasa. Seguro de su victoria "al primero lugar, luego al segundo, / tercero, cuarto, quinto y sexto, abrasan, / con sed rabiosa, y con furor insano / a cuantos hallan privan de la vida" (f. 68v).

Narra también el ataque a la plaza fuerte de Cataro defendida heroicamente por Matteo Bembo, y como estando allí, al recibir la noticia de que la armada mandada por Juan de Austria está en Mesina, "el sagaz Ochialí levanta el cerco, / a Cataro dejando, en cuya fuerza / halló tal resistencia, dando al viento / la blanca vela, el puerto deja libre. / La vuelta de Lepanto lleva, y llega / adonde el gran Bajá lo está esperando" (f. 77v). Pero antes de dirigirse a Lepanto el rey de Argel embarca más soldados, hasta llegar a un número de 24.000 .

En la descripción de la batalla el poeta exalta la argucia y habilidad del calabrés que no solo consigue salvarse, sino que hace estragos en las galeras de Malta hasta que viendo acabada la flota otomana que se creía invencible y considerando que si permanece en la lucha será alcanzado:
"Tomando el estandarte y seña honrada desa religión que a Malta ilustra. huye el sagaz tirano, siempre teme, y del vecino mal no se asegura, con grande turbación mil veces mira, si Cristiana galera en pos vaya.
Con riguroso azote el renegado hace doblar el remo y rasga el agua: llevando allí volando el mar y el viento con una amarillez mortal de rostro" (f. 202r).

El poeta nos deja esta última imagen de Uchalí alejándose de la batalla para no caer en manos de sus enemigos, y llevando consigo el estandarte de la nave de Malta como testimonio de la victoria conseguida sobre los caballeros de San Juan. 


\section{Uchalí en los textos dramáticos de Lope de Vega y Vélez de Guevara}

La presencia de Uchalí en el panorama teatral español del Siglo de Oro está estrechamente ligada a su protagonismo en la batalla de Lepanto, pero no en todas las obras dramáticas que ponen en escena la famosa batalla aparece la figura de Uchalí. Además de una mención que hemos encontrado en La nueva victoria del marqués de Santa Cruz de Lope de Vega en la cual Fátima, al comienzo de primera jornada, al narrar a Alí Bajà que era la nieta del general Alí muerto en la batalla de Lepanto, se refiere a Uchalí de manera despectiva, ${ }^{25}$ hay dos comedias que, desarrollando el tema de la victoria naval de la Santa Liga, incluyen entre las dramatis personae al renegado calabrés: La Santa Liga de Lope de Vega y El águila del agua de Luis Vélez de Guevara. ${ }^{26}$

En La Santa Liga, ${ }^{27}$ visto el marcado tono épico-celebrativo de la comedia, los personajes otomanos, que revisten el papel de antagonistas de los cristianos, como es obvio en una distribución maniquea de los roles, están caracterizados con los habituales estereotipos negativos. El único al que Lope confiere una connotación relativamente positiva es Uchalí. En efecto, en esta obra, al contrario de La Nueva victoria del marqués de Santa Cruz, el dramaturgo lo presenta come un musulmán valiente, hábil estratega y atento a los intereses políticos y militares del imperio otomano, y estos rasgos se evidencian a lo largo de toda la comedia.

Por ejemplo, en la segunda jornada, cuando ya había empezado la toma de Chipre por parte de los turcos, la intervención de Uchali se revela determinante para el éxito de la guerra. El renegado calabrés, habiendo sabido que a causa de la rivalidad amorosa entre los generales Mustafá y Alí, prendados ambos de Constancia, estaba en peligro la ocupación de la isla, va a Chipre y amonesta severamente a los generales censurando su conducta indigna y echándoles en cara que descuidando su deber de soldados estaban poniendo en entredicho la conquista de Nicosia que solo se podía conseguir luchando juntos contra los enemigos del imperio turco.

25 Dice Fátima: "no era tan Aquiles como Ulises / ni tan Pirro como César" (p. 186); poco después le llama cobarde: "Si como Uchalí cobarde/ mi abuelo famoso fuera,/ y volviera las espaldas/ con tan vergonzosa afrenta,/ nunca el español Don Juan / en Mesina las banderas/ de Selín vuestro señor/ arrastrara con vergüenza" (pp. 186-87). Citamos de la edición de la viuda de Pedro Verges (Parte XXV), Zaragoza, 1647.

26 Es plausible pensar que en la desaparecida Batalla naval que Cervantes menciona entre sus obras teatrales en la "Adjunta" al Viaje al Parnaso y en el "Prólogo" a Ocho comedias, uno de los personajes fuese el "tiñoso calabrés", como lo define el autor en el Quijote.

27 Citamos de la edición de la viuda de Alonso Martín, Madrid, 1621. 
Dice Uchalí: "No estuviera Nicosia / en pie si junta estuviera / vuestra heroica valentía / ni aquí Venecia pudiera / socorrella cada día (ff. 106r-106v). Pero no le resultó muy fácil al rey de Argel convencerlos para que abandonaran la contienda amorosa y se dedicaran a combatir a sus enemigos, los cristianos. Solo después de una larga y animada discusión en la que resulta claro que Costanza no quiere a ninguno de los dos, y de la decisión de Uchalí de devolver la esclava a su marido (el capitán Leonardo defensor de Famagusta), consigue que Alí y Mustafá sellen la paz y tomen la isla.

Otro episodio significativo que pone en evidencia la prudencia del estratega Uchalí, es cuando, en la ultima jornada, ya constituida la Santa Liga, Mustafa, Alí y Uchalí se reúnen para discutir sobre la utilidad de entrar en guerra contra la armada naval cristiana. El calabrés, valorando prudentemente las fuerzas adversarias, considera más conveniente volver a Constantinopla victoriosos y con un botín de "quince mil vidas prisioneras" que afrontar la armada cristiana $y$, sabiamente, aconseja a los generales que no subestimen la potencia naval de la coalición cristiana: "ni aquí solo se embarcan españoles; / el gobierno de cuerdos venecianos / a sus galeras sirve de faroles, / franceses, genoveses y romanos, / con los de Malta, en la milicia soles, /vienen juntos aquí, mirad que os digo, / que el sabio no desprecia al enemigo" (ff. 126r-136v). Alí interpreta las palabras de Uchalí como un acto de cobardía y pusilanimidad de quien, a pesar de ser superior en número, teme al adversario, y pregunta retóricamente: " ¿Volveremos, por dicha, las espaldas / al cristiano don Juan, mozo orgulloso, / como mujeres de cobardes faldas? (f. -136v). Mustafá, en cambio, pone en duda su auténtica conversión al islamismo y considera que su actitud está dictada porque, como tantos otros renegados, en lo íntimo de su alma continúa siendo cristiano, por eso dice a Alí: "Alí, como Uchalí cristiano ha sido, / aún debe de tener cristiana el alma; / vuelve por el cristiano, que vencido, / él mismo ofrece la victoria y palma. (f. 136v). Ante la actitud despectiva de los generales, que incluso le dicen que si no quiere combatir se vaya con su escuadra, Uchalí reacciona con fuerza reafirmando su fidelidad al sultán y asegurándoles que participará en la batalla.

En la última parte de la obra, para dramatizar la batalla naval, Lope introduce tres figuras alegóricas, España, Roma y Venecia, que van narrando en ticoscopia las diversas fases. Y es precisamente a Uchalí, entre los generales otomanos, a quien dedican mayor espacio: España reproduce la arenga que el rey de Argel hace a sus jenízaros; Roma describe el choque entre Uchalí y la galera de Malta, y luego Venecia informa de cómo, al darse cuenta de la victoria cristiana, sale huyendo y toma puerto en la playa. Después sale a escena Uchali maldiciendo su suerte y diciendo que 
con razón temió la fuerza cristiana y que Alí, por no haberle creído, tiene ahora su cabeza en una pica. Y termina su actuación imprecando contra Mahoma y ordenando a sus hombres que pongan ruta a su reino de Argel:
"A pesar de Mahoma, ¿̇con qué cara
en la del Gran Señor pareceremos?
Diremos que a Filipo el cielo ampara
o que Pio Quinto es santo le diremos.
Hasta la tierra aquí se vende cara;
largad las velas y moved los remos,
llevadme a Argel, reniego de Mahoma,
o a Meca, porque allí sus huesos coma" (f. 117r).

Palabras que dejan muchos puntos interrogativos sobre el sentido que Lope quiere dar, sobre todo considerando que antes Alí ha insinuado una posible conversión solo exterior del renegado, y que ahora, ante la derrota otomana, el propio Uchalí reconoce que los cristianos han contado con la ayuda divina mientras que a los mahometanos no les ha sucedido lo mismo.

En El águila del agua de Vélez de Guevara, ${ }^{28}$ aunque Uchalí tiene un papel secundario, pues interviene solo en la última jornada y recita solo unos sesenta versos, sin embargo su función es indispensable en la economía de la obra, ya que es el único general otomano que actúa en la comedia. En efecto, manipulando la historia, el dramaturgo lo hace intervenir en las tablas no como personaje que se sitúa en el plano de la realidad histórica representada, es decir, comandante del ala derecha turca opuesta a la izquierda de la escuadra cristiana, sino como el comandante de la "real del Gran Turco", configurándolo así come el directo contrincante de Don Juan.

El hecho de que Vélez haya elegido a Uchalí como el único representante de los comandantes de la escuadra otomana, quizá se pueda explicar por el reflejo de la fama que adquirió después de la batalla naval, a la que seguramente contribuyó el retrato que Cervantes hizo de él en el Quijote ${ }^{29}$ y que se difundió por toda España. Por lo tanto, era un personaje fácilmen-

28 Citamos de la edición de MANSON William R. y PEALE George (2003).

29 Vélez hace varias alusiones a la obra cervantina e incluso la cita directamente, por ejemplo, cuando Escamilla dice que un galeote se pasa la mayor parte del tiempo leyendo y Almendruca responde: "Don Quijote es de la Mancha". 
te reconocible y que el público teatral asociaría, sin duda, como el turco más valeroso que los cristianos tuvieron como antagonista en la batalla de Lepanto.

Como hemos dicho, Uchalí entra en escena en el último acto cuya acción transcurre casi toda en la galera Real española capitaneada por don Juan de Austria. Antes de entablar la batalla el hampón Escamilla, que había sido condenado por la justicia a servir en la galera Real por asesino, en un largo parlamento cuenta a los otros condenados y a su daifa Almendru$\mathrm{ca}$, los hechos que han llevado al gran enfrentamiento naval y concluye diciendo que trecientas galeras turcas están llegando a Lepanto y que los generales que han sido nombrados para esta hazaña son "Luch Alí, Pi Alí y Siroco / tres galgos de buena casta" (vv. 2964-65, p. 206). Al acabar su discurso, suena un pito, señal que don Juan está embarcado en la Real, y todos se preparan para tomar los remos.

Nada más zarpar la galera de don Juan, entra en escena Uchalí "turco y con bengala" que sobre la popa de su galera dirige una arenga a sus soldados. El largo parlamento, único discurso que Vélez pone en boca de Uchalí, sirve al dramaturgo para caracterizar negativamente al personaje definiéndolo con claridad como enemigo de los españoles y de la Cristiandad. En esta larga secuencia de silvas pareadas, haciendo recurso a juegos metafóricos, referencias mitológicas, cultismos, Uchalí incita a sus "jenízaros valientes" exhortándolos:

$$
\begin{aligned}
& \text { "a castigar la armada del Poniente } \\
& \text { y su pretexto loco } \\
& \text { con Luch Alí Baiá, Pi Alí y Siroco, } \\
& \text { vuestros tres generales, } \\
& \text { del sol antorchas y de Alá fanales, } \\
& \text { y contra los que engaña } \\
& \text { esta vil liga de Venecia, España, } \\
& \text { y el alfaquí de Roma" (vv.3164- 3171). }
\end{aligned}
$$

Pero, sobre todo, los anima a terminar con la arrogancia de don Juan, destruyendo su armada para que así "queden de tan soberbia loca armada / las glorias españolas / por navales despojos de las olas" (vv. 3206-3208, p. 214).

Y la comedia acaba con una escena cómica protagonizada por los dos graciosos: el hampón Escamilla llevando estandarte turco en la boca y los 
dos hijos del Bajá debajo de los brazos y Almendruca con un medio remo diciendo a don Juan: "¡Aténgome a Pero Vázquez / de Escamilla, de gloriosa / memoria, y al medio remo / con que he espantado las moscas / a Luch Alí!" (vv.3607-6611). Al final, queda patente que Vélez a través de las palabras de Almendruca ridiculiza y degrada a Uchalí, convirtiendo al famoso renegado calabrés, al enemigo per antonomasia de los españoles, en un personaje risible.

\section{CONCLUSIÓN}

Después de este breve recorrido sobre la figura histórica de Uchalí y por la imagen que de él nos presentan los cronistas y poetas coevos y los dramaturgos de la primera mitad del siglo XVII, podemos decir que, a pesar de las distintas opiniones e interpretaciones que los autores hacen de este legendario personaje, que de esclavo llegó a ser uno de los corsarios más temidos y respetados en todo el Mediterráneo, no hay duda de que en general se le considera un gran estratega y como uno de los hombres más singulares de su tiempo. Es el paradigma del renegado, que no se resigna a su mísera suerte de esclavo y elige el único camino que encuentra primero para salvar su vida y luego para medrar. Pero esta elección hace que en un mundo fronterizo y maniqueo, para unos sea un héroe digno de admiración mientras que para otros sea un hombre despreciable y cruel. Pero lo que es innegable es que sus gestas se propagan por todo el Mediterráneo convirtiéndose ya en vida en un ser legendario cantado o denigrado por cronistas y poetas.

Su fama llegó a ser tal que hasta el mismo rey de España se preocupa de seguir sus movimientos y se crea en torno a él una red de espionaje; como hemos podido verificar en los numerosos documentos conservados en el Archivo de Simancas, el monarca español está muy bien informado sobre todo lo relacionado con el rey de Argel, prueba de ello es la correspondencia que intercambia, directa o indirectamente, con el duque de Medinaceli, el marqués de Pescara, Andrea Doria, Alonso de la Cueva, Alonso Pimentel y otros personajes notables, ${ }^{30}$ sobre todo a partir del momento en que algunos esclavos se amotinan contra Uchalí en 1562 y tratan de matarlo sin conseguirlo. Los documentos de Simancas también dan prueba de los intentos, después de la batalla de Lepanto, por conseguir que el renegado calabrés volviera a la religión cristiana y se pusiera al servicio del rey. Una serie de cartas, algunas de ellas cifradas, de don Juan de Austria fechadas en Mesina entre el 20 y 21 de 1571 son clara prueba de ello. 
El intermediario era el capitán Pedro Pablo de Arcuri que había sido renegado muchos años y que era amigo de Uchalí, al cual el héroe de Lepanto da instrucciones escritas para cumplir su cometido. Las instrucciones son que le recuerde que fue cristiano y que procure aprovechar la ocasión que se le ofrece de volver a su tierra y familia muy honrado y que él le ofrece en nombre del rey grandes mercedes "y que él puede pedir las que más le contentaren, y dexar sobre mi palabra el cumplimento de lo que se le prometerá, aunque si quisiere algún género de dignidad que se le pueda dar también se le dará, a su contentamiento". ${ }^{31}$ El servicio que pide don Juan a cambio es: o que encuentre la forma de dar al rey, Argel y Tripoli, o alzarse con una banda de bajeles turcos $O$, en altarnativa, dar alguna plaza importante. Pero nada de esto sucede, Uchalí sigue hasta el final de su vida fiel al sultán.

\section{BIBLIOGRAFÍA}

ALVES, Helio J. S. (1998), Jerónimo Corte-Real, Poesia, Angelus Novus Editora, Braga-Coimbra.

CAMAMIS, George (1977), Estudios sobre el cautiverio en el Siglo de Oro, Gredos, Madrid.

CERVANTES, Miguel de (1987), El ingenioso hidalgo Don Quijote de la Mancha, Gredos, Madrid.

CERVANTES, Miguel de (2019), Información de Argel, ed. Sáez Adrián, Catedra, Madrid.

CIORANESCU, Alexandre (1952), "Un poème inconnu de Don Pedro Manrique", Mélanges Mario Roques, París, pp. 37-49.

CORTE REAL, Jerónimo (1575), Espantosa y felicissima victoria concedida del cielo al señor don Juan de Austria en el golfo de Lepanto de la poderosa armada othomana, en el año de nuestra salvación de 1572 (sic), compuesta por leronimo Corte-Real cauallero Portugués, año de mil y quinientos $L X X V$.

COSTIOL, Hierónimo (1572), Primera Parte de la Chrónica del muy poderoso Príncipe don luan de Austria hijo del Emperador Carlo quinto. De las jornadas contra el gran Turco Selimo Il començada en la pérdida del reyno de Chipre: tratando primero de genealogía de la casa Ottomana. Dirigido al Illustrissi. y Excellentis. Señor Don Hernando de Toledo, Prior de Castilla Visorey, y Lugarteniente de su Magestad en el Principado de Cataluña, y de su Consejo supremo, etc. Copiada por Hierónymo de Costiol, Viuda de Bartolomé de Nágera, Zaragoza. 
DAVIS, Robert (2004), Christian slaves, muslin masters: white slavery in the Mediterranean, the Barbary Coast, and Italy, 1500-1800, Palgrave Macmillan, Londres.

EISENBERG, Daniel (1996), "Cervantes, autor de la Topografía e historia general de Argel publicada por Diego de Haedo", Cervantes: Bulletin of the Cervantes Society of America, vol. 16.1, pp. 32-53.

HAEDO, Fray Diego de (1612), Topographía e Historia general de Argel, repartida en cinco tratados do se verán casos estraños, muertes espantosas, y tormentos exquisitos, que conviene se entiendan en la Christiandad: con mucha doctrina, y elegancia curiosa dirigida al Ilustríssimo señor Don Diego de Haedo Arzobispo de Palermo, Presidente, y Capitán General del Reyno de Sicilia, Diego Fernández de Córdoua y Ouiedo Impressor, Valladolid. HERRERA, Fernando (1572), Relación de la guerra de Cipre, y suceso de la batalla naval de Lepanto, escrita por Fernando de Herrera; dirigido al llustrísimo y Ecelentísimo Señor Don Alonso Pérez de Guzmán El Bueno, duque de Median Sidonia, y conde de Niebla, Alonso Escrivano Impressor, Sevilla. KAISER, Wolfgang (2006), "Frictions profitables. L'économie de la rançon en Méditerranée occidental XVle-XVIlle siècles", en CAVACIOCCHI, Simonetta (ed.), Ricchezza del mare, ricchezza dal mare. Secc. XIII-XVIII, Le Monnier, Florencia, vol. II, pp. 689-701.

KAISER, Wolfgang (2008), Le commerce des captifs: les intermédiaires dans l'echange des prisonniers en Mediterranée, XVe-XVIIle siècles, École Française de Roma, Roma.

LOPES DE ALMEIDA, Manuel (1979), Obras de Jerónimo Corte Real. Sucesso do segundo cerco de Diu. Náufragio de Sepúlveda. Auto dos quatro novissimos do homem. Elegias, Lello \& Irmão Editores, Oporto.

LÓPEZ DE TORO, José (1950), Los poetas de Lepanto, Instituto Histórico de Marina, Madrid.

MANRIQUE, Pedro (s.a.), La naval, Ms. 3942, BNE.

MARTINI, Gian Giacomo (1635), Consiliorum sive responsorum iuris D. loan. lacobi Martini I. C. Calabri a Sancto Nicolao a lunca, et eiusdem Ecclesiae Maioris Abb. Curati. Volumen Primum. Opus omnibus V. I. peritis, tam in Pontificio, quam Cesareo lure versantibus apprime necessarium, et utile, et bonarium artium, politicae, et Historiarum amatoribus non iniucundum, cum argumentis, et indice omnium rerum, et sententiarum locupletissimo, Alphabetico ordine digesto, Sancti Nicolai, Apud Joannem Baptistam Russo, et Dominicum lezzo.

MARTIRE, Domenico (1887), Calabria sacra e profana, Tip.Migliaccio, Cosenza. 
SALAZAR Y CASTRO, Luis de (1694), Pruebas de la historia de la Casa de Lara sacadas de los instrumentos de diversas iglesias y monasterios, de los archivos de sus mismos descendientes, de diferentes pleitos que entre sí han seguido y de los escritores de mayor crédito y puntualidad, Imprenta Real, Madrid.

SOLA, Emilio (1991), "Antonio de Sosa: Un clásico inédito amigo de Cervantes", Actas del I Congreso Internacional de la Asociación de Cervantistas, Anthropos, Barcelona, pp. 409-412.

SOLA, Emilio (2010), Uchalí. El calabrés Tiñoso, o el mito del corsario muladí en la frontera, Ediciones Bellaterra, Barcelona.

TETI, Vito (2009), "Gian Giacomo Martini e Uluccialì alias Kiliç Alì Pasha: aspetti della costruzione dell'identità calabrese tra XVI e XVII secolo", en ANSELMI, Alessandra (ed.), La Calabria del Viceregno Spagnolo. Storia arte architettura, Gangemi Editore, Roma, pp. 139-169.

VALENTE, Gustavo (1973), Calabria Calabresi e Turcheschi nei secoli della pirateria (1400-1800), Framas's, Chiaravalle Centrale, p. 134.

VALENTE, Gustavo (1960), La vita di Occhiali. Da schiavo a Re di Tunisi, Tripoli e Algeri, Editrice Ceschina, Milano-Varese.

VATIN, Nicolas (2001), Les ottomans et l'occident (XVe-XVle siècles), Isis, Estambul.

VEGA, Lope de (1621), La Santa Liga, Viuda de Alonso Martín, Madrid.

VEGA, Lope de (1647), La nueva victoria del Marqués de Santa Cruz, Viuda de Pedro Vergés, Zaragoza.

VELEZ DE GUEVARA, Luis (2003), El águila del agua, Juan de la Cuesta, Delaware. 